\title{
CAMINANTE, SE HACE CAMINO AL ANDAR. COMUNIDAD LGTBI, DERECHOS HUMANOS Y NACIONES UNIDAS*
}

\author{
Walker, road is done when walking. \\ LGTBI Community, Human Rights and United Nations
}

\author{
Ignacio Álvarez Rodríguez ${ }^{1}$ \\ Profesor Ayudante Doctor de Derecho Constitucional \\ Universidad Complutense de Madrid \\ ialvarez1@ucm.es \\ http://dx.doi.org/10.18543/ed-67(1)-2019pp127-163 \\ Recibido: 01.02.2019 \\ Aceptado: 21.06.2019
}

\section{Resumen}

El presente estudio ofrece un análisis de las principales medidas que se han adoptado por la Organización de las Naciones Unidas para garantizar los derechos humanos de las personas LGTBI.

\section{Palabras clave}

Derechos humanos; LGTBI; ONU.

* Cómo citar / Citation 'Chicago-Deusto' (Autor-fecha / Author-date / Lista de referencias / Reference list entries): Álvarez Rodríguez, Ignacio. 2019. «Caminante, se hace camino al andar. Comunidad LGTBI, derechos humanos y Naciones Unidas». Estudios de Deusto 67, n. ${ }^{\circ}$ 1: 127-163. http://dx.doi.org/10.18543/ed-67(1)-2019pp127-163.

${ }^{1}$ El presente trabajo se ha realizado en el marco del Proyecto de Investigación DER2016-75993, sobre España ante Europa: retos nacionales en materia de derechos humanos (2016-2020). IP: Francisco Javier MATIA PORTILLA. 


\section{Abstract}

The paper aims to study the tools and measures implemented by the United Nations in order to achieve and reinforce the LGBTI human rights.

\section{Keywords}

Human Rights; LGBTI; UN. 
SuMARIO: I. PlanteAmiento. II. LA COMUNIDAD LGTBI A LO LARGO Y ANCHO DEL MUNDO. 1. Una comunidad en expansión. 2. Una comunidad que mejora y empeora. III. LA COMUNIDAD LGTBI EN EL MARCO DE NaCIONES UnidAS. 1. Mecanismos de protección basados en la Carta de Naciones Unidas. 1.1. El Consejo de Derechos Humanos y el Alto Comisionado de Naciones Unidas para los Derechos Humanos. 1.2. El Examen Periódico Universal. 1.3. El Experto Independiente sobre Orientación Sexual e Identidad de Género. 2. Protección desde el Derecho Internacional de los Derechos Humanos. 2.1. Comité de Derechos Humanos. 2.2. Comité contra la Tortura. 3. Protección desde otros órganos. 3.1. El Alto Comisionado de las Naciones Unidas para los Derechos Humanos. 3.2. Secretaría General. IV. UN BALANCE CRÍtico. 1. Sobre lo que se ha hecho. 2. Prospectiva de futuro. V. CONCLUSIONES. VI. Bibliografía.

\section{PLANTEAMIENTO}

Hace algún tiempo se pudo estudiar los derechos humanos de la comunidad LGTBI $^{2}$ dentro de la Organización de Naciones Unidas ${ }^{3}$. Con el presente se quiere ofrecer un análisis que actualice las principales decisiones y

${ }^{2}$ Se emplearán las siguientes abreviaturas: ACNUDH-Alto Comisionado de las Naciones Unidas para los Derechos Humanos; CEDH-Convenio Europeo de Derechos Humanos; CT-Convenio contra la Tortura; DUDH-Declaración Universal de los Derechos Humanos; EPU-Examen Periódico Universal; ILGA-International Lesbian and Gay Association; LGTBI-Lesbianas, Gays, Transexuales, Bisexuales, Intersexuales; ONG-Organización No Gubernamental; ONU-Organización de Naciones Unidas PIDCP-Pacto Internacional de Derechos Civiles y Políticos; TEDH-Tribunal Europeo de Derechos Humanos.

3 ÁLVAREZ RODRÍGUEZ, Ignacio: «La Organización de las Naciones Unidas y el derecho a la no discriminación por motivo de orientación sexual e identidad de género: apuntes para un debate». En Revista General de Derecho Constitucional 17 (2013): 1-30. Dentro de la doctrina española destaca el trabajo de MONEREO ATIENZA, Cristina: Diversidad de género, minorías sexuales y teorias feministas (Madrid: Dykinson, 2015); también puede verse BILBAO UBILLOS, Juan María; y MORETÓN TOQUERO, María Aranzazu; «Protección de los derechos humanos en España. Marco normativo». En Rey Martínez, Fernando (dir).: Los derechos humanos en España: un balance crítico. Tirant lo blanch, Valencia, 2015, pp. 29-33. Por lo demás, España lidera en primera posición el ranking internacional que elabora Equaldex. De una Encuesta realizada a treinta y nueve países por el Pew Research Center, el 88\% de la población española respondió afirmativamente a la pregunta: «¿Debe la sociedad aceptar la homosexualidad?» (el 11\% respondió que no). Además, cumplimos con otros indicadores que nos llevan a auparnos a esa posición (matrimonio homosexual legalizado; adopción de parejas del mismo sexo permitida; la discriminación contra las personas LGTBI está prohibida al máximo nivel, siendo considerada agravante penal; se permite el cambio de sexo-género de la persona incluso 
medidas que se han adoptado en la materia ${ }^{4}$. Para ello, y una vez que se exponga brevemente el estado de la cuestión de los derechos de las personas LGTBI a nivel mundial, se procederá siguiendo un triple esquema. En primer lugar, se abordan los mecanismos de protección de los derechos humanos basados en la Carta de Naciones Unidas. En segundo lugar se hará lo propio con los mecanismos de protección basados en el Derecho Internacional de los Derechos Humanos. Finalmente, en tercer lugar se estudiará la labor de protección de otros organismos. De este triple análisis se deduce un balance crítico sobre las acciones acometidas y se da algunas pistas sobre las que podrían acometerse. El trabajo se cierra con las pertinentes conclusiones, sometidas al mejor criterio de la doctrina.

\section{LA COMUNIDAD LGTBI A LO LARGO Y ANCHO DEL MUNDO}

Los derechos de las personas LGTBI viven en la actualidad una situación un tanto extraña. Por un lado, es una comunidad en plena expansión, vital y de todo orden. Por otro, se constatan casi a partes iguales avances y retrocesos a lo largo y ancho del globo, y además de forma simultánea ${ }^{5}$. Es, pues, una materia para el análisis micro y no macro. Se entremezclan avances reales y conquistas sociales con atropellos varios ${ }^{6}$. Con todo, la

sin cirugía de por medio; y así un largo etcétera). Vid. http://www.equaldex.com/region/ spain (consultado el 15 de enero de 2019).

${ }_{4}$ Vid. PEÑA DÍAZ, Francisco de Asís: La lucha que no cesa. Los derechos del colectivo LGTBI como derechos humanos. Tirant lo Blanch, Valencia, 2018. Una contribución colectiva con abundante información puede verse en HELLUM, Anne (ed): Human Rights, Sexual Orientation and Gender Identity. Routledge, Oxon-New York, 2017. Desde la doctrina internacional puede verse ALSTON, Philip; y GOODMAN, Ryan; International Human Rights, Oxford University Press, Oxford, 2013, especialmente pp. 220 y ss. Desde un plano general, estudiando los valores que hay detrás de estas reivindicaciones son interesantes las reflexiones de CLIFFORD, Jarlath; «Equality». En Shelton, David (ed.); The Oxford Handbook of International Human Rights Law. Oxford University Press, Oxford, 2013, pp. 420-445; y de CAROZZA, Paolo: «Human Dignity». En Shelton, David (ed.); The Oxford Handbook of International Human Rights Law, Oxford University Press, Oxford, 2013, pp. 345-359.

5 Aunque es un asunto discutido y discutible, la doctrina apunta a tres como las causas de persecución de la comunidad LGTBI: la cultura patriarcal; la configuración jerárquica y binaria del género; y el patrón heteronormativo de las relaciones afectivo-sexuales. Vid. DÍAZ LAFUENTE, José: Asilo y refugio por motivos de orientación sexual e identidad de género. Congreso de los Diputados, Madrid, 2016, p. 30 y ss.

${ }_{6}$ La doctrina identifica hasta tres etapas dentro de las reivindicaciones del movimiento. Un primer momento que tiene lugar a partir de las décadas de los setenta-ochenta del pasado siglo, donde se reivindica la autonomía y la libertad en el ámbito privado (despenalización de la homosexualidad). Una segunda que se inaugura en los años noventa, 
tendencia global parece clara: la liberalización en el mundo occidental es un hecho contrastado ${ }^{7}$.

\section{Una comunidad en expansión}

Un ejemplo ilustrativo de los avances referidos es el del acrónimo LGTBI. Es importante hacer notar que en su origen la expresión englobaba a la comunidad de personas lesbianas, gays, transexuales y bisexuales (LGTB). Pero a medida que ha ido pasando el tiempo, a medida que la diversidad ha ido tomando cuerpo, y a medida que se ha profundizado y desarrollado su mundo y sus peculiaridades, el acrónimo no ha hecho sino crecer, lo cual implica ciertos disenso a la hora de referirse a estos colectivos. El que suele ser más leído es LGTBI (Lesbianas, Gays, Transexuales, Bisexuales e Intersexuales). Pero también se ha visto LGTBIQ (Lesbianas, Gays, Transexuales, Bisexuales, Intersexuales y Queers) y su versión evolucionada e inclusiva en forma de $L G T B I Q+$. También se ha visto el $L G T B Q I A+$, con la «A» en plena discusión: para unos significa asexual; para otros, significa agénero; para los de más allá puede ser aliado. También se ha leído LGBQTIIA (Lesbiana, Gay, Bisexual, Transgénero, Queer, Indeterminado, Intersexual, Asexual) o incluso el de LGBTQIIAAP (a la anterior se añaden Aliados y Pansexuales) ${ }^{8}$. Por lo demás, la doctrina internacionalista suele preferir dejarlo en $L G B$, por estimar que los derechos de transexuales, transgénero e intersexuales plantean algunos retos diferentes de los que plantean los derechos de las personas homosexuales y bisexuales ${ }^{9}$.

Sea como fuere, lo importante no es tanto el acrónimo sino lo que viene antes: las personas; por más que la reivindicación se haga de modo grupal no deja de haber personas detrás. Y eso es lo verdaderamente importante.

donde la lucha se centra en la igualdad y la no discriminación en el ámbito público (estrategia antidiscriminatoria). Y la tercera, que es la que se estaría desarrollando en la actualidad y que podría llamarse «de iguales derechos y reconocimiento público» (matrimonio, adopción). Todo esto tiene, como bien sabemos, su cuota de críticos, tanto desde dentro del movimiento («son instituciones puramente burguesas que le hacen el juego al sistema») como desde fuera («el matrimonio es y sólo es para parejas heterosexuales»). Vid. MONEREO ATIENZA, Cristina: Diversidad..., cit, p. 69 y ss.

7 Vid. PINKER, Steven: En defensa de la Ilustración. Paidós, Barcelona, 2018, p. 280 y ss. Específicamente sobre la materia que nos ocupa, vid. VOSS, M. Joel: «Contesting Sexual Orientation and Gender Identity at the UN Human Rights Council». En Human Rights Review 19 (2018), pp. 1-22; y TIRADO CHASE, Anthony: «Human rights contestations: sexual orientation and gender identity». En The International Journal of Human Rights 20 (2016), pp. 703-723.

8 Vid. ZIZEK, Slavoj: El coraje de la desesperanza. Crónicas del año en que actuamos peligrosamente, Anagrama, Barcelona, 2018, pássim.

9 Vid. ALSTON, Philip; y GOODMAN, Ryan; International..., cit, nota al pie 13. 


\section{Una comunidad que mejora y empeora}

Los principales avances que se han producido en el respeto y reconocimiento de los derechos de las personas LGTBI difieren mucho en función de la zona del mundo que se analice. Si posamos la mirada en África, hay decisiones muy loables, como por ejemplo la adoptada por un Tribunal Superior de Botsuana, que ordenó al gobierno cambiar la mención relativa al sexo que figuraba en el documento de identidad de una mujer transgénero, y determinó que su negativa a hacerlo no era razonable y conculcaba los derechos de la mujer. Si vamos a las Américas, vemos el caso de Bolivia, donde el Defensor del Pueblo del país propuso modificar el Código Penal para tipificar como delito los crímenes de odio contra personas LGBTI. Si acudimos a la zona de Asia y Oceanía, se observan avances reales y ciertos en Japón (a nivel local) y en Taiwán. Así, las autoridades de la ciudad de Osaka reconocieron por primera vez a una pareja homosexual como progenitores de acogida, y dos municipios más avanzaron hacia el reconocimiento de las uniones entre personas del mismo sexo. Por su parte, Taiwán, gracias a un histórico fallo de su más alto tribunal, estaba cerca de convertirse en el primer país asiático que legalizaba el matrimonio entre personas del mismo sexo. Los jueces resolvieron que la ley taiwanesa sobre el matrimonio era inconstitucional en tanto que discriminaba a las parejas del mismo sexo, y dieron a los parlamentarios un plazo de dos años para reformar o promulgar la legislación pertinente. Respecto a Europa y Asia Central, destacan algunas novedades positivas. La Red LGBT rusa organizó una línea telefónica de emergencia y facilitó la evacuación de personas LGBTI a lugares seguros desde Chechenia y otros lugares del Cáucaso Septentrional. En Ucrania se celebró el mayor desfile del Orgullo Gay jamás organizado allí. El Parlamento de Malta aprobó legislación sobre el matrimonio entre personas del mismo sexo y amplió todos los derechos del matrimonio a las parejas homosexuales. Por su parte, Alemania reconoció los derechos del matrimonio a todas las parejas, con independencia del género o la orientación sexual, así como los mismos derechos en materia de adopción que las parejas casadas. Finalmente, en Oriente Medio y Norte de África lo más reseñable es que las cuestiones relativas a la orientación sexual y la identidad de género estaban incluidas cada vez más en las agendas de los movimientos tradicionales de derechos humanos de la región (y menos en buena parte de sus gobiernos) ${ }^{10}$.

10 Toda la información se ha extraído de AMNISTÍA INTERNACIONAL: Informe 2017-2018. La situación de los derechos humanos en el mundo, Londres, 2018 (https:// crm.es.amnesty.org/sites/.../Informeanual2018air201718-spanish\%20web.pdf. Consultado el 2 de diciembre de 2018). También puede consultarse la abundante información que suministra HUMAN RIGHTS WATCH, en su página web institucional: https://www. hrw.org/es/topic/derechos-de-personas-lgbt (consultado el 13 de diciembre de 2018). Para 
Desafortunadamente, también existen serios retrocesos en la materia. Así, en África, las personas LGBTI sufrieron discriminación, hostigamiento, persecución y violencia en países como Senegal, Ghana, Malawi y Nigeria. En uno de ellos (Ghana), el presidente del Parlamento pidió una modificación constitucional para que la homosexualidad fuera considerada ilegal y punible por ley. En Liberia, un hombre detenido en 2016 y acusado de «sodomía voluntaria» en virtud del Código Penal permanecía recluido en espera de juicio. En Nigeria se denunciaron detenciones, humillaciones públicas, extorsiones y discriminación de personas por su orientación sexual. En las Américas, los gobiernos no avanzaron mucho en la protección de los derechos de lesbianas, gays, bisexuales, transgénero e intersexuales, con violencia generalizada contra estas personas en países como Brasil, El Salvador, Honduras, México y Venezuela, por citar algunos. En Asia y Oceanía se constata una discriminación amplia en la vida pública de la población LGTBI en Corea del Sur. En Malasia, Papúa Nueva Guinea y Singapur sucede otro tanto. En Australia se ha observado un incremento del discurso del odio contra ellas. Y como siempre hay quien quiere ganar a todo, inclusive en crueldad, tenemos el caso de Indonesia, donde se azotó ochenta y tres veces a dos hombres por mantener relaciones sexuales consentidas. En Europa y Asia Central existen diversos gobiernos apelando a los «valores tradicionales» para encubrir discriminaciones contra las personas LGTBI ${ }^{11}$. Rusia es uno de los ejemplos paradigmáticos. Y el caso de Chechenia es espeluznante, donde se han producido secuestros, torturas y muertes en secreto de varios homosexuales. Desgraciadamente, tenemos más ejemplos, como el de Azerbaiyán (más de cien personas LGBTI fueron detenidas arbitrariamente en un solo día); el de Uzbekistán y Turkmenistán (las relaciones sexuales consentidas entre hombres seguían siendo delito castigado con la cárcel); y/o el de Georgia (en su nueva Constitución se restringió la definición de matrimonio para excluir a las parejas del mismo sexo). En Oriente Medio y Norte de África, el panorama es más sombrío, si cabe. En Egipto las autoridades detuvieron y enjuiciaron a multitud de personas por su presunta orientación sexual tras la exhibición pública de una bandera con el arcoíris. Las fuerzas de seguridad detuvieron al menos a setenta y seis personas y sometieron a exámenes anales, práctica que

ampliar puede verse REID, Graeme: «Lucha global por los derechos de las personas LGBT». En Política Exterior 157 (2014), pp. 1-8. Resalta la importancia de este tipo de organizaciones LAMARCA ITURBE, Iñigo: «El deber de disponer de políticas públicas a favor de la igualdad para las personas LGTB, tanto en los ámbitos nacionales como internacionales». En SOROETA LICERAS, Juan: La diversidad afectivo-sexual y los mecanismos establecidos por el Derecho Internacional para su protección. Thomson Reuters, Cizur Menor, 2015, p. 252 y ss.

${ }_{11}$ REID, Graeme: «La homofobia como estrategia política». En Política Exterior 167 (2015), pp. 126-136. 
constituye tortura según todos los estándares internacionales, como mínimo a cinco. Los tribunales condenaron al menos a casi cincuenta de esas personas a entre tres meses y seis años de prisión por cargos como hábitos licenciosos. En octubre, un grupo de parlamentarios propuso una ley profundamente discriminatoria que penalizaba de manera expresa las relaciones homosexuales y toda promoción pública de reuniones, símbolos o banderas LGBTI. En otros países, verbigracia Marruecos y Túnez, se siguió deteniendo a personas y condenándolas a prisión en aplicación de leyes que penalizaban las relaciones homosexuales consentidas. En Túnez, aunque la policía sometía a los hombres acusados de relaciones homosexuales a exámenes anales forzados, el gobierno aceptó la recomendación, formulada en el examen periódico universal de la ONU en septiembre, de poner fin a esta práctica. En otros países, como Irán y Arabia Saudí, algunas conductas homosexuales consentidas siguen estando sujetas a pena de muerte. Casi nada.

El grueso de datos expuesto queda refrendado en casi todos los Informes que han analizado el problema, bien los elaborados por organismos públicos, bien los realizados por organizaciones no gubernamentales ${ }^{12}$, bien en trabajos académicos ${ }^{13}$. La única noticia buena es que todos esos países forman parte de la principal organización internacional a nivel mundial. Y la pregunta deviene inevitable: ¿qué ha hecho la ONU a la hora de proteger los derechos de las personas LGTBI en estos últimos cuatro años? ¿Ha conseguido reducir las malas prácticas (por llamarlas de algún modo)? ¿Ha conseguido integrar a los países menos convencidos? Para responder a los interrogantes debemos acudir al siguiente epígrafe.

\section{LA COMUNIDAD LGTBI EN EL MARCO DE NACIONES UNIDAS}

Aquí se va a prestar atención a las dos grandes formas de proteger los derechos humanos que tiene la ONU. La primera se basa en la protección conferida por la Carta de Naciones Unidas (especialmente, la Declaración

12 Vid. PALETTA, Daniele (coord.; y ed.), y PLESSIS, A. Du (dir): Informe Anual, ILGA, 2017. En el marco de dicha asociación es esclarecedor el trabajo de CARROLL, Aengus; y MENDOS, Lucas Ramón: Homofobia de Estado, ILGA, 2017 (12ª edición). Por lo demás, la relevancia de esta federación mundial no sólo se acredita por aglutinar a más de mil doscientas organizaciones de ciento treinta y dos países que lleva luchando por los derechos LGTBI desde el año 1978 sino también por haber conseguido el estatus de organismo consultivo de Naciones Unidas. Vid. MONEREO ATIENZA, Cristina: Diversidad..., cit. p. 62. Esto generó en su día una auténtico y profundo rechazo por parte de los países de siempre. Vid. LAMARCA ITURBE, Iñigo: «El...», cit, p. 258 y ss.

13 Vid. ALVENTOSA DEL RÍO, Josefina: «Derechos humanos y orientación sexual e identidad de género». En Rey Martínez, Fernando (dir).: Los derechos humanos en España: un balance crítico. Tirant lo blanch, Valencia, 2015, pp. 736-781. 
Universal de los Derechos Humanos). La segunda se basa en la protección que otorga el Derecho Internacional de los Derechos Humanos.

\section{Mecanismos de protección basados en la Carta de Naciones Unidas}

En primer lugar, haremos referencia al Consejo de Derechos Humanos. En segundo término, se hará lo propio con el Examen Periódico Universal. En tercer lugar se hace lo propio con el Experto Independiente en Orientación Sexual e Identidad de Género, una de las principales novedades en la materia ${ }^{14}$.

\subsection{El Consejo de Derechos Humanos y el Alto Comisionado de Naciones Unidas para los Derechos Humanos}

Es sabido que el Consejo de Derechos Humanos fue una institución que vio la luz en 2006 y que sustituyó a la extinta Comisión de Derechos Humanos. La tarea tuvo especial mérito teniendo en cuenta «el clima anti-derechos humanos» que se había generado en la escena internacional después del $11-\mathrm{S}^{15}$.

Así pues, estamos ante un organismo intergubernamental dentro del sistema de las Naciones Unidas compuesto por cuarenta y siete Estados, asumiendo la responsabilidad en la promoción y protección de los derechos humanos en todo el mundo, sin distinción de ningún tipo y de manera justa y equilibrada ${ }^{16}$. Tiene un mandato específico y autónomo en lo que hace a

${ }^{14}$ El Consejo también ha abordado asuntos relacionados con la orientación sexual e identidad de género en asuntos relativos a las ejecuciones judiciales, sumarias y arbitrarias así como en asuntos relacionados con detenciones arbitrarias. Vid. ALVENTOSA DEL RÍO, Josefina: «Derechos...», cit; p. 741.

15 Vid. NOWAK, Manfred: «De la Comisión de Derechos Humanos al nuevo Consejo». En Almqvist, Jessica; y Gómez Isa, Felipe (coords.); El Consejo de Derechos Humanos. Oportunidades y Desafios. Universidad de Deusto, Bilbao, 2006, pp. 13-22. Para profundizar en la cuestión puede verse VILLÁN DURÁN, Carlos: «Luces y sombras del nuevo Consejo de Derechos Humanos», En Almqvist, Jessica; y Gómez Isa, Felipe (coords.); El Consejo de Derechos Humanos. Oportunidades y Desafios. Universidad de Deusto, Bilbao, 2006, pp. 23-36; ALMQVIST, Jessica: «El Consejo de Derechos Humanos: un paso audaz hacia derechos efectivos para todos». En Almqvist, Jessica; y Gómez Isa, Felipe (coords.); El Consejo de Derechos Humanos. Oportunidades y Desafios. Universidad de Deusto, Bilbao, 2006, pp. 37-46; y OCHOA RUIZ, Natalia; y SALAMANCA AGUADO, Esther: «El Consejo de Derechos Humanos de las Naciones Unidas. Un análisis preliminar». En Revista Electrónica de Estudios Internacionales 12 (2006), pp. 1-27.

16 Así lo establece la Resolución 60/251, de la Asamblea General, de 15 de marzo de 2006. Vid. OCHOA RUIZ, Natalia; y SALAMANCA AGUADO, Esther: «El Consejo...», cit, p. 14 y ss. 
intentar garantizar que el disfrute de aquellos se haga libre de discriminación ${ }^{17}$. Su vocación es sin duda holística y omnicomprensiva: todas las personas deben estar en condiciones de disfrutar de todos los derechos sin trazas de violencias, amenazas o cualesquiera hechos y/o actos que impidan su normal desenvoltura.

Qué duda cabe que esta tarea no la puede realizar en solitario. Y, con el antecedente del Informe del ACNUDH, sobre «Leyes y prácticas discriminatorias y actos de violencia cometidos contra personas por su orientación sexual e identidad de género», de $2011^{18}$; y una vez que se discutieron sus principales líneas en la Mesa Redonda que se celebró bajo los auspicios del propio Consejo el 7 de marzo de $2012^{19}$, llegó la Resolución 27/32, del Consejo de Derechos Humanos, de 2 de octubre de 2014, sobre Derechos humanos, orientación sexual, e identidad de género, donde se eleva una petición a dicho Alto Comisionado para que actualice el Informe ${ }^{20}$.

En menos de un año el ACNUDH cumple el encargo y evacua el texto «Discriminación y violencia contra las personas por motivos de orientación sexual e identidad de género», presentado al propio Consejo el 4 de mayo de $2015^{21}$. El nuevo Informe es, si cabe, más detallado y exhaustivo que el primero. Una vez da cuenta de las principales normas que imperan en la materia -recordemos, fundamentalmente centradas en proteger a las personas de todo tipo de violencia, de prevenir la tortura y cualesquiera malos tratos, de despenalizar legislativamente la homosexualidad, de derogar toda ley que castigue a las personas por su orientación sexual y/o identidad de género, de proteger a las personas de sufrir cualquier discriminación por estos motivos,

17 Corroborado por la Resolución 17/19, del Consejo de Derechos Humanos, de 17 de junio de 2011, primera en la en la Historia de Naciones Unidas que trata sobre orientación sexual e identidad de género, con un criterio de plena vigencia hasta el día de hoy: hacer realidad la Declaración Universal de los Derechos Humanos para todos. Vid. GARTENBERG, Micha (dir); y BLANK, Edan (codir); United Nations Human Rights Council. Protection of LGTB Youth, CJMUNG, 2018, p. 5.

${ }_{18}$ El Informe se ha leído aquí: https://www.ohchr.org/Documents/Issues/ Discrimination/A.HRC.19.41_spanish.pdf (consultado el 12 de diciembre de 2018).

19 A instancias de Brasil y Sudáfrica se discutieron algunos aspectos sensibles en materia de no discriminación por orientación sexual e identidad de género, con diversos representantes de otros tantos países de procedencias muy diversas (organizaciones no gubernamentales, Universidades, Centros de Investigación, e incluso expertos del Consejo de Europa) Detallado en su página web oficial: https://www.ohchr.org/SP/HRBodies/ HRC/RegularSessions/Session19/Pages/19RegularSession.aspx. (Consultada el 13 de enero de 2019).

${ }^{20}$ La Resolución puede leerse aquí: https://www.ohchr.org/SP/hrbodies/hrc/pages/ documents.aspx (consultado el 13 de enero de 2019).

${ }^{21}$ El Informe se ha leído aquí: www.acnur.org/5b6c527b4.pdf (consultado el 12 de enero de 2019). 
así como de proteger los derechos fundamentales básicos de estos colectivos (libre expresión, libre asociación, libre reunión, y libre participación en la dirección de los asuntos públicos)- aborda dos grandes ámbitos. En primer lugar, el de la violencia homofóbica y transfóbica, dando cuenta de hechos y casos concretos acaecidos en diferentes países. Se abre un rayo de esperanza al final del apartado, toda vez que constata diversos progresos en la materia. En segundo lugar, el de la discriminación; aquí opera de forma similar: narra primero sucesos concretos y posteriormente hace balance de conjunto, donde destaca diversas despenalizaciones de estas conductas, modificaciones constitucionales concretas para introducir prohibiciones de discriminación específicas, y una miríada de iniciativas que van desde protocolos de actuación en sede judicial donde se ventilen este tipo de casos, hasta medidas específicas laborales que pretenden proteger a los miembros de estos colectivos, pasando por diversos programas contra el acoso y la persecución en escuelas, fábricas, y diversos ámbitos públicos y privados.

El Informe finaliza con tres tipos de conclusiones y recomendaciones; unas dirigidas a los Estados; otras dirigidas a las llamadas «Instituciones nacionales de derechos humanos»; y las restantes encaminadas a hacer saber al Consejo que el ACNUDH sigue dispuesto a trabajar en la causa. Las que tienen mayor relevancia son, sin duda, las que se dirigen a los Estados. Para combatir la violencia recomienda, entre otras medidas, que «a) Promulguen leyes sobre los delitos motivados por prejuicios que establezcan la homofobia y la transfobia como factores agravantes a los efectos de la determinación de las penas; b) Investiguen sin demora y de manera exhaustiva los incidentes de violencia motivada por el odio y de tortura de personas LGBT, exijan responsabilidades a los autores y proporcionen reparación a las víctimas; c) Recaben y publiquen datos sobre el número y los tipos de incidentes registrados, velando al mismo tiempo por la seguridad de los denunciantes; d) Prohíban la incitación al odio y la violencia por motivos de orientación sexual e identidad de género, y exijan responsabilidades a quienes pronuncien esos discursos de odio $»^{22}$. Para combatir la discriminación, recomienda a los

${ }^{22}$ Otras de las medidas que proponen llaman a los Estados a que: (se) «e) Familiaricen al personal responsable de hacer cumplir la ley y a los jueces con los enfoques sensibles a las cuestiones de género para tratar las vulneraciones motivadas por la orientación sexual y la identidad de género; f) Velen por que la policía y los funcionarios de prisiones reciban la capacitación necesaria para proteger la seguridad de las personas LGBT presas, y exijan responsabilidades a los funcionarios estatales que participen o sean cómplices en incidentes de violencia; g) Prohíban las terapias de «conversión», los tratamientos involuntarios, la esterilización forzada y los exámenes genitales y anales forzados; h) Prohíban los procedimientos innecesarios desde el punto de vista médico en niños intersexuales; i) Velen porque no se devuelva a ninguna persona que huya de la persecución por su orientación sexual o identidad de género a un territorio donde su vida o libertad estarían ame- 
Estados, por ejemplo, «a) Revisar las leyes penales para destipificar las conductas sexuales consentidas entre personas del mismo sexo y otros delitos utilizados para detener y castigar a personas por su orientación sexual y su identidad o expresión de género; ordenar una moratoria inmediata sobre los enjuiciamientos conexos; y eliminar los antecedentes penales de quienes hayan sido declarados culpables de dichos delitos; b) Derogar las denominadas leyes «antipropaganda» y cualquier otra ley que imponga restricciones discriminatorias a la libertad de expresión, asociación y reunión; c) Velar por que la legislación contra la discriminación incluya la orientación sexual y la identidad de género entre los motivos prohibidos de discriminación y proteja también a las personas intersexuales contra la discriminación ${ }^{23}$.

Por lo demás, el Consejo de Derechos Humanos ha auspiciado diversas acciones e iniciativas adicionales. Destacar a título de ejemplo la Declaración Pública Poner fin a la violencia y a la discriminación contra las

nazada s y por que las leyes y las políticas de asilo reconozcan que la persecución por la orientación sexual o la identidad de género puede ser un motivo válido para una solicitud de asilo; y eliminen los interrogatorios intrusivos e inapropiados sobre las historias sexuales de los solicitantes de asilo y sensibilicen al personal que trata con los refugiados y los solicitantes de asilo»

${ }^{23}$ También aboga por: «d) Integrar el análisis de las vulneraciones motivadas por la orientación sexual y la identidad de género en los planes de acción nacionales para asegurar la coordinación y la asignación de recursos adecuados a las actividades conexas, la rendición de cuentas de los autores y la reparación de las víctimas; e) Sensibilizar a los profesionales de la salud en cuanto a las necesidades sanitarias de las personas LGBT e intersexuales, en particular en los ámbitos de la salud y los derechos sexuales y reproductivos, la prevención del suicidio y el asesoramiento sobre el VIH/SIDA y los traumas; f) Establecer normas nacionales sobre la no discriminación en la educación; elaborar programas contra el acoso y crear líneas telefónica s y otros servicios de ayuda a las personas jóvenes LGBT y a las que muestran una disconformidad de género; y proporcionar una educación sexual integral adecuada en función de la edad; g) Velar por que las políticas sobre la vivienda no discriminen a los inquilinos por motivos de orientación sexual o identidad de género; y establecer centros de acogida para las personas LGBT sin hogar, prestando una atención específica a los jóvenes, a las personas de edad y a las que se encuentran en situaciones de emergencia; $h$ ) Reconocer, por ley a las parejas del mismo sexo y a sus hijos, de modo que las prestaciones tradicionalmente concedidas a las parejas casadas -como las relacionadas con las pensiones, los impuestos y la herencia- se concedan en términos no discriminatorios; i) Expedir, a quienes los soliciten, documentos legales de identidad que reflejen el género preferido del titular, eliminando los requisitos abusivos, como la esterilización, el tratamiento forzado y el divorcio; j) Financiar campañas públicas de educación contra las actitudes homofóbicas y transfóbicas, y combatir la difusión de imágenes negativa s y estereotípicas de las personas LGBT en los medios de comunicación; k) Velar por que se consulte a las personas LGBT e intersexuales y a las organizaciones que las representan en relación con la legislación y las políticas que afecten a sus derechos». 
personas lesbianas, gais, bisexuales, trans e intersex, de septiembre de $2015^{24}$, donde recuerda a los Estados más olvidadizos que la Organización está de su lado y podrá ayudarles en el proceso de erradicar de sus usos, costumbres y legislaciones el castigo de la sexualidad e identidad contramayoritaria.

\subsection{El Examen Periódico Universal}

También en el marco del Consejo de Derechos Humanos se realiza el llamado Examen Periódico Universal (EPU), un análisis de los expedientes de derechos humanos de todos los Estados Miembros de las Naciones Unidas ${ }^{25}$. En él se ofrece la oportunidad a cada Estado de exponer qué medidas ha adoptado para mejorar la situación de los derechos humanos en el país. Resulta indiscutible que su objetivo final es mejorar la situación de derechos humanos en todos los países y abordar las violaciones de los derechos humanos donde quiera que se produzcan. ¿Qué podemos destacar en lo que hace a la protección de las personas LGTBI?

En la actualidad, el EPU se encuentra en pleno Tercer Ciclo (2017-2021), por lo que podemos ofrecer algunas pautas de los países que recientemente han sido objeto de evaluación (refiriéndonos exclusivamente a la orientación sexual y la identidad de género) ${ }^{26}$. De ese modo, podemos traer el caso de Liechenstein (Informe de 2018), cuyo examen ha saludado la reforma legal que se introdujo en 2016 y que enmienda su Código Penal para castigar hasta con dos años de cárcel cualquier tipo de discriminación, así como de incitación pública al odio, entre otros motivos, por orientación sexual. También podemos referirnos al caso de Alemania (Informe de 2018), donde se saluda la creación de diferentes leyes antidiscriminatorias y la puesta en marcha de administraciones específicamente dirigidas a tal fin (el Organismo Federal contra la Discriminación).

En otro eje de coordenadas se sitúa, por ejemplo, el caso de Argentina (Informe de 2017), donde se refieren algunos avances en la materia junto al recordatorio de la existencia y subsistencia de cierta violencia institucional contra la comunidad LGTBI que debe ser erradicada. En un supuesto similar se encuentra Ecuador (Informe de 2017), donde conviven las reformas

${ }^{24}$ Se ha leído aquí: http://www.unaids.org/es/resources/presscentre/pressreleaseandstatementarchive/2015/september/20150929_LGBTI (consultado el 13 de enero de 2019).

${ }_{25}$ Vid. KOTHARI, Miloon: «From Comission to the Council: Evolution of UN Charter Bodies». En Shelton, David (ed.); The Oxford Handbook of International Human Rights Law. Oxford University Press, Oxford, 2013, pp. 587-620.

${ }^{26} \mathrm{La}$ información de este apartado se ha extraído de: https://www.ohchr.org/sp/hrbodies/upr/pages/uprmain.aspx (consultado el 14 de enero de 2019). 
legales que han introducido la tipificación del delito de discriminación por motivo de orientación sexual e identidad de género junto a prácticas tan aberrantes como el internamiento forzoso en «centros de rehabilitación» de personas lesbianas, gays, bisexuales, transgénero e intersexuales.

Finalmente destacan los países más avanzados en la materia (efectivamente los nórdicos/escandinavos). Podemos poner por caso paradigmático Finlandia, donde desde hace algunos años existe una Ley de Reconocimiento Jurídico del Género de los Transexuales, equipada con medios y dotaciones suficientes para realizar las reasignaciones de género por la sanidad pública. El principal problema que observa la Comunidad Internacional, y así lo recoge la ONU (Informe de 2017) es que todavía se exige que las personas sean esterilizadas o estériles como condición para el reconocimiento legal de la reasignación de género. Incluso el mejor escribano echa un borrón.

\subsection{El Experto Independiente sobre Orientación Sexual e Identidad de Género}

El Consejo de Derechos Humanos adoptó el 30 de junio de 2016 la Resolución 32/2, de Protección contra la violencia y la discriminación por motivos de orientación sexual e identidad de género ${ }^{27}$. Mediante la misma se crea la figura del Experto Independiente sobre orientación sexual e identidad de género. Su régimen jurídico se puede resumir en tres apuntes, que se cerrarán con un par de reflexiones críticas.

En primer término, la figura se ha creado por un periodo de tres años y es elegida por el Consejo de Derechos Humanos (el primer Experto fue el tailandés Vitit Muntarnhorn, cuyo mandato se ha desarrollado del 1 de noviembre de 2017 a octubre de 2017; en la actualidad ostenta el cargo el costarricense Víctor Madrigal-Borloz, desde el 1 de enero de 2018).

En segundo término, el mandato específico que se le atribuye se divide en varias áreas. La primera es evaluar la aplicación de los instrumentos internacionales vigentes de derechos humanos relacionados con los medios de superar la violencia y la discriminación contra las personas por motivos de orientación sexual o identidad de género, e identificar las mejores prácticas y las deficiencias. La segunda, alude a concienciar a la población acerca de la violencia y la discriminación contra las personas por motivos de orientación sexual o identidad de género, y determinar y abordar las causas fundamentales de la violencia y la discriminación. La tercera reside en entablar un diálogo con los Estados y otros interesados pertinentes, incluidos los organismos, programas y fondos de las Naciones Unidas, los mecanismos regionales de

${ }^{27}$ La Resolución puede leerse aquí: https://www.ohchr.org/SP/hrbodies/hrc/pages/ documents.aspx (consultado el 14 de enero de 2019). 
derechos humanos, las instituciones nacionales de derechos humanos, las organizaciones de la sociedad civil y las instituciones académicas, y celebrar consultas con ellos; instituciones académicas, y celebrar consultas con ellos. La cuarta es trabajar, en cooperación con los Estados, para promover la aplicación de medidas que contribuyan a la protección de todas las personas contra la violencia y la discriminación por motivos de orientación sexual o identidad de género. La quinta se refiere a hacer frente a las formas múltiples, interrelacionadas y agravadas de violencia y discriminación con que se enfrentan las personas por causa de su orientación sexual o identidad de género. Y la sexta versa sobre organizar, facilitar y apoyar la prestación de servicios de asesoramiento, asistencia técnica, fomento de la capacidad y cooperación internacional en apoyo de las iniciativas nacionales de lucha contra la violencia y la discriminación de las personas por motivos de orientación sexual o identidad de género. En cumplimiento de esas tareas, la Resolución exige del Experto que presente sendos informes anuales al Consejo de Derechos Humanos y a la Asamblea General.

En tercer lugar, destacan sus métodos de trabajo. Así, goza de tres grandes herramientas. La primera, la recopilación y estudio de la información que recabe de los diferentes países, gozando de la facultad de transmitirles llamamientos urgentes y denuncias individuales. La segunda, la visita in situ a los países que estime oportuno, especialmente a aquellos que presenten algunas inconsistencias a la hora de proteger a las personas LGTBI. Y la tercera, las recomendaciones generales y particulares que formule a tales Estados.

A pesar de que estamos ante la creación de un mecanismo saludable y necesario, no todos comparten la opinión. Sacar adelante la Resolución y sacar adelante el mandato fue muy costoso. De los 47 Estados, 23 votaron a favor, 18 en contra, y 6 se abstuvieron ${ }^{28}$. Y eso que se consiguió introducir una serie de párrafos en la misma que venían a ser un canto sensible al respeto multicultural ${ }^{29}$.

${ }^{28}$ No es casualidad que los países que votaron en contra son países donde se viven realidades muy duras respecto a los derechos humanos en general, y respecto a la situación de la personas LGTBI en particular. Por eso se suele decir-lamentablemente, con razón- que «los derechos de las personas LGBT son de manera casi invariable una piedra de toque de la situación de los derechos humanos en general, y su represión suele tener lugar en el contexto de una represión más amplia». Vid. REID, Graeme: «Lucha...», cit, p. 3. Algunos expertos creen que los avances reales se producen más como consecuencia de la acción y presión de diversos movimientos políticos y sociales a favor de estos colectivos que por el hecho de que grandes potencias patrocinen iniciativas como la presente. Así lo ve TIRADO CHASE, Anthony: «Human...», cit, p. 717.

29 De muestra, varios botones: «Reiterando la importancia de respetar los sistemas de valores culturales y religiosos regionales, así como las particularidades en la manera de considerar las cuestiones de derechos humanos». «Subrayando la importancia fundamental 
Lo cierto y verdad es que el Experto Independiente ha seguido adelante con su tarea. Desde su creación hasta la actualidad ha llevado todas y cada una de las tareas exigidas (y alguna más) ${ }^{30}$. Por razones evidentes de espacio no podemos entrar en profundidad en ellas, pero sí realizar un breve bosquejo. El primer hito reseñable fue el Informe «Diversidad en la humanidad, humanidad en la diversidad», de 19 de abril de 2017, presentado al Consejo de Derechos Humanos en su $35^{\circ}$ periodo de sesiones, celebrado entre el 6 y el 23 de junio de $2017^{31}$. El siguiente hito es el Informe «Acepta la diversidad e impulsa la humanidad», de 19 de julio de 2017, presentado a la Asamblea General en su $72^{\circ}$ periodo de sesiones $^{32}$. Después destacan diferentes visitas que ha realizado a otros tantos países. Primero a Argentina, misión que tuvo lugar entre el 1 y el 10 de marzo de 2017 y cuyo Informe final se ha elaborado el 9 de abril de 2018 (y presentado al Consejo de Derechos Humanos en su $38^{\circ}$ periodo de sesiones, del 18 al 6 de julio de 2018 ${ }^{33}$. Después a Georgia, con una visita celebrada entre el 25 de septiembre y el 5 de octubre de 2018, que no tiene todavía Informe de balance pero

de respetar los debates pertinentes a nivel nacional sobre cuestiones relacionadas con la sensibilidad histórica, cultural, social y religiosa». «Deplorando el uso desde el exterior de medidas de presión y coercitivas contra algunos Estados, en particular países en desarrollo, tales como el uso o la amenaza de uso de sanciones económicas o la aplicación de condicionalidad a la asistencia oficial para el desarrollo, con el fin de influir en los debates y los procesos de decisión pertinentes a nivel nacional». «Preocupado por todo intento de socavar el sistema internacional de derechos humanos tratando de imponer conceptos o nociones relativas a cuestiones sociales, incluida la conducta individual privada, que quedan al margen del marco jurídico de los derechos humanos convenido internacionalmente, y teniendo en cuenta que dichos intentos reflejan un desconocimiento del carácter universal de los derechos humanos». «Subrayando que la presente resolución debería aplicarse, garantizando al mismo tiempo el respeto del derecho soberano de los países y sus leyes nacionales, las prioridades de desarrollo, los distintos valores religiosos y éticos y los patrimonios culturales de su población, y que debería ser plenamente conforme con los derechos humanos internacionales reconocidos universalmente». Expertos en la materia dan cuenta de que se puede haber reproducido la lógica del «Choque de civilizaciones» en el Consejo -extrapolable al resto de organismos de derechos humanos de la ONU- por la «imposición de un nuevo catálogo de derechos». Vid. VOSS, M. Joel: «Contesting...», cit, p. 19.

${ }^{30}$ Por poner un ejemplo concreto: el Experto no ha dudado en emitir recientemente una Declaración Pública condenando la violencia global contra comunidad trans. Vid. https:// www.ohchr.org/EN/NewsEvents/Pages/DisplayNews.aspx?NewsID=23775\&LangID=E (consultado el 16 de enero de 2019).

31 Puede leerse el Informe aquí: https://www.ohchr.org/SP/NewsEvents/Pages/GenderIdentityReport.aspx (consultado el 16 de enero de 2019).

32 Puede leerse el Informe aquí: https://www.ohchr.org/SP/Issues/SexualOrientationGender/Pages/AnnualReports.aspx (consultado el 16 de enero de 2019).

33 Puede leerse aquí: http://acnudh.org/informe-del-experto-independiente-sobreorientacion-sexual-o-identidad-de-genero-mision-a-la-argentina/ (consultado el 16 de enero de 2019). 
sí una declaración pública del Experto abogando porque el país adopte todas las medidas necesarias para el reconocimiento de la realidad de las personas LGTBI, así como la legislación necesaria a tal fin ${ }^{34}$. Y finalmente a Mozambique, misión que ha completado entre el 2 y el 10 de diciembre de 2018, donde, a pesar de que tampoco existe todavía Informe final, ha dejado una declaración pública y exigente para con las autoridades mozambiqueñas, reconociendo sus aciertos e impulsando la voluntad de subsanar errores ${ }^{35}$.

\section{Protección desde el Derecho Internacional de los Derechos Humanos}

La ONU goza de una serie de tratados internacionales que protegen específicamente alguno o varios derechos humanos. Cada uno de estos tratados suele llevar aparejado un mecanismo de protección específico, un órgano colegiado formado por miembros de los diferentes países firmantes del correspondiente Tratado. Estos órganos, aunque se asemejan en cierta medida a los tribunales (se habla de que sus resoluciones son jurisprudencia), en puridad son órganos más políticos que jurídicos, sin que sus decisiones sean más vinculantes de lo que el Estado afectado de turno decida ${ }^{36}$.

En esta materia concreta y para al arco temporal consabido destacan en total ocho resoluciones. Seis de ellas decididas por el Comité de Derechos Humanos (mecanismo de protección del PIDCP); y dos ellas decididas por el Comité contra la Tortura (mecanismo de protección del CT) ${ }^{37}$.

${ }^{34}$ Puede leerse aquí: https://www.ohchr.org/en/NewsEvents/Pages/DisplayNews. aspx? NewsID=23682\&LangID=E (consultado el 16 de enero de 2019).

35 Adelantando que la tarea debe realizarse en cuatro frentes. Primero, que dichas autoridades conozcan y reconozcan la realidad de su población LGTBI; segundo, que investiguen las conocidas como «terapias de conversión»; tercero, que implementan campañas de sensibilización en todos los sectores; y cuarto, que formulen políticas públicas y protocolos en dicho sentido, especialmente legislación anti-discriminación en todos los ámbitos. Puede verse dicha declaración aquí: https://www.ohchr.org/EN/NewsEvents/Pages/DisplayNews. aspx? NewsID=24002\&LangID=E (consultado el 16 de enero de 2019).

${ }^{36}$ Sobre esta cuestión puede verse RODLEY, Nigel S: «The role and impact of treaty bodies». En Shelton, David (ed.); The Oxford Handbook of International Human Rights Law. Oxford University Press, Oxford, 2013, pp. 621-648. Se calcula que la media de cumplimiento de estas resoluciones viene siendo de menos de la mitad. Vid. FERNÁNDEZ LIESA, Carlos: El Derecho Internacional de los Derechos Humanos en perspectiva histórica. Aranzadi, Cizur Menor, 2013, p. 453. Al fin y al cabo, «la clave para una mejor protección de los derechos humanos se encuentra en profundizar en el diálogo entre los órganos y los Estados, incidir en la cooperación con estos y movilizar los recursos adecuados. Así lo afirma OCHOA RUIZ, Natalia: Los mecanismos convencionales de protección de los derechos humanos en Naciones Unidas. Civitas, Madrid, 2004, p. 430.

37 Todas las resoluciones se han consultado aquí: http://juris.ohchr.org/es (consultado el 13 de diciembre de 2018). 


\subsection{Comité de Derechos Humanos}

La labor del Comité de Derechos Humanos respecto a la protección de las personas LGTBI continua la senda marcada en los noventa del pasado $\operatorname{siglo}^{38}$. En el periodo de los últimos cuatro años destacan seis casos, ventilados en 2017 y 2016, donde se alega la vulneración de varios preceptos del Pacto, especialmente los contemplados en los artículos 26 y $27^{39}$.

Comenzando por 2017, en dicho año se ventilaron los casos C. c. Australia; G. c. Australia; y M.Z.B.M. c. Dinamarca.

En el caso $C$ c. Australia (Dictamen aprobado el 28 de marzo de 2017, referencia CCPR/C/119/D/2216/2012) se plantea demanda ante el Comité porque la actora entiende que la denegación de acceso al divorcio a las parejas del mismo sexo por parte de la legislación australiana, siendo el matrimonio contraído legítimamente en el extranjero, es un acto de discriminación por orientación sexual, que atentaría contra dos derechos reconocidos en el Pacto: el derecho de acceso a los tribunales en condiciones de igualdad (para obtener la correspondiente sentencia de divorcio, en lectura conjunta de los artículos 14 y 2 del Pacto) ${ }^{40}$, y el derecho a la igualdad ante la ley (artículo 26

${ }^{38}$ Sigue siendo señero el principal criterio emanado de su jurisprudencia; y es que el artículo 26 PIDCP prohíbe que cualquier persona sea discriminada, también, por motivos de orientación sexual e identidad de género. Este fue el famoso «criterio Toonen» (nombre del primer caso donde lo estableció, en 1994). Ese criterio se ha mantenido hasta la actualidad. Vid. DÍAZ LAFUENTE, José: «El derecho a la igualdad y a la no discriminación por motivos de orientación sexual». En CUESTA LÓPEZ, Víctor Manuel; y SANTANA VEGA, Dulce María (coords.); Estado de Derecho y discriminación por razón de género, orientación e identidad sexual. Thomson Reuters, Cizur Menor, 2014, p. 312 y ss. Destaca la labor del Comité ALVENTOSA DEL RÍO, Josefina: «Derechos...», cit. p. 754 y ss.

39 Artículo 26 PIDCP: «Todas las personas son iguales ante la ley y tienen derecho sin discriminación a igual protección de la ley. A este respecto, la ley prohibirá toda discriminación y garantizará a todas las personas protección igual y efectiva contra cualquier discriminación por motivos de raza, color, sexo, idioma, religión, opiniones políticas o de cualquier índole, origen nacional o social, posición económica, nacimiento o cualquier otra condición social». Artículo 27 PIDCP: «En los Estados en que existan minorías étnicas, religiosas o lingüísticas, no se negará a las personas que pertenezcan a dichas minorías el derecho que les corresponde, en común con los demás miembros de su grupo, a tener su propia vida cultural, a profesar y practicar su propia religión y a emplear su propio idioma».

40 Artículo 2 PIDCP: «1. Cada uno de los Estados Partes en el presente Pacto se compromete a respetar y a garantizar a todos los individuos que se encuentren en su territorio y estén sujetos a su jurisdicción los derechos reconocidos en el presente Pacto, sin distinción alguna de raza, color, sexo, idioma, religión, opinión política o de otra índole, origen nacional o social, posición económica, nacimiento o cualquier otra condición social. 2. Cada Estado Parte se compromete a adoptar, con arreglo a sus procedimientos constitucionales y a las disposiciones del presente Pacto, las medidas oportunas para dictar las disposiciones legislativas o de otro carácter que fueren necesarias para hacer efectivos los derechos reconocidos en el presente Pacto y que no estuviesen ya garantizados por disposiciones legislativas o de otro carácter. 
del Pacto). Para la actora, dicha denegación no queda justificada ni objetiva ni razonablemente, criterios más que asentados en la jurisprudencia del Comité, así como en diversos tribunales internacionales como el TEDH, del

3. Cada uno de los Estados Partes en el presente Pacto se compromete a garantizar que: a) Toda persona cuyos derechos o libertades reconocidos en el presente Pacto hayan sido violados podrá interponer un recurso efectivo, aun cuando tal violación hubiera sido cometida por personas que actuaban en ejercicio de sus funciones oficiales; b) La autoridad competente, judicial, administrativa o legislativa, o cualquiera otra autoridad competente prevista por el sistema legal del Estado, decidirá sobre los derechos de toda persona que interponga tal recurso, y desarrollará las posibilidades de recurso judicial; c) Las autoridades competentes cumplirán toda decisión en que se haya estimado procedente el recurso». Artículo 14 PIDCP: «1. Todas las personas son iguales ante los tribunales y cortes de justicia. Toda persona tendrá derecho a ser oída públicamente y con las debidas garantías por un tribunal competente, independiente e imparcial, establecido por la ley, en la substanciación de cualquier acusación de carácter penal formulada contra ella o para la determinación de sus derechos u obligaciones de carácter civil. La prensa y el público podrán ser excluidos de la totalidad o parte de los juicios por consideraciones de moral, orden público o seguridad nacional en una sociedad democrática, o cuando lo exija el interés de la vida privada de las partes o, en la medida estrictamente necesaria en opinión del tribunal, cuando por circunstancias especiales del asunto la publicidad pudiera perjudicar a los intereses de la justicia; pero toda sentencia en materia penal o contenciosa será pública, excepto en los casos en que el interés de menores de edad exija lo contrario, o en las acusaciones referentes a pleitos matrimoniales o a la tutela de menores. 2. Toda persona acusada de un delito tiene derecho a que se presuma su inocencia mientras no se pruebe su culpabilidad conforme a la ley. 3. Durante el proceso, toda persona acusada de un delito tendrá derecho, en plena igualdad, a las siguientes garantías mínimas: a) A ser informada sin demora, en un idioma que comprenda y en forma detallada, de la naturaleza y causas de la acusación formulada contra ella; b) A disponer del tiempo y de los medios adecuados para la preparación de su defensa y a comunicarse con un defensor de su elección; c) A ser juzgado sin dilaciones indebidas; d) A hallarse presente en el proceso y a defenderse personalmente $o$ ser asistida por un defensor de su elección; a ser informada, si no tuviera defensor, del derecho que le asiste a tenerlo, y, siempre que el interés de la justicia lo exija, a que se le nombre defensor de oficio, gratuitamente, si careciere de medios suficientes para pagarlo; e) A interrogar o hacer interrogar a los testigos de cargo y a obtener la comparecencia de los testigos de descargo y que éstos sean interrogados en las mismas condiciones que los testigos de cargo; f) A ser asistida gratuitamente por un intérprete, si no comprende o no habla el idioma empleado en el tribunal; g) A no ser obligada a declarar contra sí misma ni a confesarse culpable. 4. En el procedimiento aplicable a los menores de edad a efectos penales se tendrá en cuenta esta circunstancia y la importancia de estimular su readaptación social. 5. Toda persona declarada culpable de un delito tendrá derecho a que el fallo condenatorio y la pena que se le haya impuesto sean sometidos a un tribunal superior, conforme a lo prescrito por la ley. 6. Cuando una sentencia condenatoria firme haya sido ulteriormente revocada, o el condenado haya sido indultado por haberse producido o descubierto un hecho plenamente probatorio de la comisión de un error judicial, la persona que haya sufrido una pena como resultado de tal sentencia deberá ser indemnizada, conforme a la ley, a menos que se demuestre que le es imputable en todo o en parte el no haberse revelado oportunamente el hecho desconocido. 7. Nadie podrá ser juzgado ni sancionado por un delito por el cual haya sido ya condenado o absuelto por una sentencia firme de acuerdo con la ley y el procedimiento penal de cada país». 
que cita alguna jurisprudencia en la materia ${ }^{41}$. Australia, por su parte, cree que buena parte de las afirmaciones de la actora carecen de pertinencia por la sencilla razón de que el matrimonio entre personas del mismo sexo no está protegido por el Pacto (tal y como confirmó el Comité en el caso Joslin y otros c. Nueva Zelanda, de 17/7/2002). Además estima que cumple el juicio de proporcionalidad en todos sus elementos y que no ha habido discriminación alguna.

El Comité considera que las razones que otorga el Estado parte no son suficientes. Con sus propias palabras: «el Comité observa que el Estado parte no justifica de manera razonable por qué los motivos que se aducen para reconocer las excepciones no son también aplicables al matrimonio contraído en el extranjero por la autora con una persona del mismo sexo. Por ejemplo, el Estado parte no ha explicado en ningún momento por qué el motivo que esgrime para que un matrimonio polígamo celebrado en el extranjero y no reconocido en Australia pueda ser objeto de un procedimiento de divorcio no es igualmente aplicable al matrimonio contraído por personas del mismo sexo en el extranjero y no reconocido en Australia. En ausencia de explicaciones más convincentes del Estado parte, el Comité considera que la diferencia de trato que se dispensa a la autora por motivo de su orientación sexual en cuanto al acceso a un procedimiento de divorcio no se funda en criterios razonables y objetivos y, por lo tanto, constituye discriminación con arreglo al artículo 26 del Pacto» (párrafo 8.6). Declara violado dicho precepto (razón bastante para no entrar a considerar si se vulneró el otro derecho alegado), exigiendo al Estado que repare la ilicitud y sus consecuencias y que en el plazo de ciento ochenta días le comunique el estado de la cuestión ${ }^{42}$.

En el caso $G$ c. Australia (Dictamen del 17 de marzo de 2017, referencia CCPR/C/119/D/2172/2012), estamos ante la negativa del Estado parte a cambiar el sexo consignado en la partida de nacimiento de una persona transgénero casada. La persona afectada recurre ante el Comité porque estima que dicha negativa lesiona diversos preceptos tanto del Pacto como de su Protocolo Facultativo, entre ellos y en lo que aquí interesa el artículo 26.

El Comité estima que «el cambio de sexo es legal en Australia y que a las personas transgénero operadas se les ofrece la posibilidad de que se les reconozca legalmente el sexo adquirido y están protegidas contra la discriminación

${ }^{41}$ Sobre el particular puede verse GILBAJA CABRERO, Estela: «Orientación sexual y Tribunal Europeo de Derechos Humanos». En Revista de Derecho Político 91 (2014), pp. 303-340.

${ }^{42}$ La decisión objeto de los votos particulares del Sr. Yadh Ben Achour (disidente), la Sra. Sarah Cleveland (concurrente), y la Sra. Anja Seibert-Fohr (disidente), a la que se ha sumado la Sra. Photini Pazartzis. 
por su condición de persona transgénero. La autora contrajo un matrimonio válido en Australia. Tras su cambio de género se le han expedido legalmente pasaportes en los que aparece como mujer, y se le ha cambiado el nombre en diversos documentos, como la partida de nacimiento, el pasaporte, el permiso de conducir y la tarjeta de atención sanitaria, entre otros. Tampoco se cuestiona el hecho de que con posterioridad al cambio de sexo la autora ha mantenido de forma cotidiana con una mujer una relación marital afectiva que el Estado parte ha reconocido como válida en todos los sentidos. No hay razón evidente para negarse a adaptar la partida de nacimiento de la autora a esta situación legalmente válida» (párrafo 7.9), lo que le lleva a afirmar que la injerencia en la vida privada familiar de la autora no es necesaria, ni proporcionada ni obedece a un interés legítimo (párrafo 7.10).

En lo que hace a la no discriminación, el Comité estima que «(...) el Estado parte (...) al negar a las personas transgénero casadas una partida de nacimiento que consigne correctamente su sexo, a diferencia del trato dispensado a las personas transgénero y demás personas no casadas, (...) no está concediendo igual protección ante la ley a la autora y a las personas que se encuentren en una situación parecida en su calidad de personas transgénero casadas. A este respecto, (...) la distinción aducida por el Estado parte no es necesaria ni proporcional a un interés legítimo, por lo que es irrazonable» (párrafo 7.4). Es por ello que el Comité «considera que la diferencia de trato entre personas casadas y no casadas que se han sometido a un procedimiento quirúrgico de afirmación del sexo y solicitan la modificación del sexo consignado en su partida de nacimiento no obedece a criterios razonables y objetivos, por lo que constituye discriminación por motivos de estado civil y condición de persona transgénero, de conformidad con el artículo 26 del Pacto» (párrafo 7.5).

Finalmente, tenemos el caso M.Z.B.M. c. Dinamarca (Dictamen de 20 de marzo de 2017, referencia CCPR/C/119/D/2593/2015), donde la actora, mujer transgénero, considera que su expulsión a Malasia vulneraría diversos preceptos del Pacto (en concreto, el artículo 7, leído conjuntamente con los artículos $17.1 ; 18.1$, y el artículo 26). En esta ocasión las cosas se desarrollaron de forma diferente. El Comité constata que: «tanto el Servicio de Inmigración de Dinamarca como la Junta de Apelaciones para Asuntos de Refugiados examinaron, de manera exhaustiva, las afirmaciones de la autora y las pruebas presentadas, pero consideraron que sus alegaciones de haber sido detenida y, en particular, de haber sido objeto de abusos sexuales adolecían de falta de fundamento e incoherencias en varios aspectos, entre ellos el número de incidentes, el momento y lugar en que sucedieron y el número de autores. A este respecto, el Comité observa que, en su comunicación, la autora describió esos incidentes de manera genérica. En cuanto a las supuestas actuaciones penales contra la autora en virtud de la ley islámica y a las 
amenazas de encarcelamiento que recibió en 2012 como resultado de dichas actuaciones, la Junta de Apelaciones para Asuntos de Refugiados también examinó los documentos del tribunal islámico que presentó la autora, pero observó que no se había dado curso a las acusaciones contra ella desde abril de 2012 y que, entre esa fecha y la partida definitiva de la autora en enero de 2014, esta había viajado al extranjero con frecuencia, sin ningún impedimento, y que durante ese tiempo no había sido detenida ni acosada en otro aspecto. En vista de esos viajes al extranjero, la Junta también puso en duda la afirmación de la autora de que el motivo por el que había retrasado su partida hasta enero de 2014 había sido la falta de medios financieros» (párrafo 7.4). Además, en el seno del proceso sustanciado ante el mismo Comité, este «observa que la autora no ha señalado ninguna irregularidad en el proceso de adopción de decisiones ni ningún factor de riesgo que las autoridades del Estado parte no hayan tenido debidamente en cuenta. Si bien la autora ha refutado la conclusión sobre los hechos a la que han llegado las autoridades de inmigración de Dinamarca, no ha explicado de qué forma el procedimiento que se siguió ante esas autoridades fue arbitrario o equivalió a una denegación de justicia» (párrafo 7.5). Por todo ello, concluye que «la expulsión de la autora a Malasia constituiría una violación de los derechos que la asisten en virtud del artículo 7 del Pacto, leído conjuntamente con los artículos 17, párrafo 1, y 26» (párrafo 7.6).

Respecto al litigio de 2016 hay que decir que el Comité resolvió un caso especialmente interesante, el caso M.K.H. c. Dinamarca (Dictamen de 12 de julio de 2016, referencia CCPR/C/117/D/2462/2014). En este supuesto el actor impugna la negativa de asilo de Dinamarca y el consiguiente riesgo que correría su vida de ser devuelto a Bangladesh, por motivo de su homosexualidad. El artículo que alega en exclusiva es el 7 (y no el 26), pero ello no es óbice para que le dediquemos algo de espacio por estar ante uno de esos supuestos bastante típicos de tratos inhumanos por la declarada homosexualidad del litigante ${ }^{43}$. En el procedimiento de solicitud de asilo el actor presentó una batería de pruebas que corroboraban que cuando vivió en Bangladesh él y su amante fueron severamente maltratados después de ser descubiertos juntos en un arrozal. De hecho, el compañero acabó perdiendo la vida cuando fue a visitar a su hermana. La persecución resultaba obvia, lacerante y reiterada. Y ese peligro no había pasado, según su parecer y según las pruebas que ameritaba. Así lo estima el Comité, estableciendo que «el Estado parte no tuvo debidamente en cuenta su versión sobre los hechos por los que pasó en Bangladesh, los documentos que proporcionó y la

43 Artículo 7 PIDCP: «Nadie será sometido a torturas ni a penas o tratos crueles, inhumanos o degradantes. En particular, nadie será sometido sin su libre consentimiento a experimentos médicos o científicos». 
información de antecedentes disponible sobre los riesgos que afrontan las personas lesbianas, gays, bisexuales y transgénero en ese país, desestimando arbitrariamente las alegaciones del autor. En tales circunstancias, el Comité considera que la expulsión del autor a Bangladesh constituiría una vulneración del artículo 7 del Pacto» (párrafo 8), por lo que insta a Dinamarca a realizar de nuevo el examen de la solicitud de asilo y a que, mientras este tenga lugar, no extradite al interesado a Bangladesh (párrafos 9 y 10$)^{44}$.

Finalmente, en 2013 se resolvió el caso Alekseev c. Federación de Rusia (Dictamen de 25 de octubre de 2013, referencia CCPR/C/109/D/1873/2009). El objeto del proceso era la denuncia del afectado contra la decisión de las autoridades rusas de prohibir todas y cada una de las reuniones pacíficas que había convocado desde la plataforma de derechos LGTBI donde participaba activamente. Tal y como lo ve el demandante «el que las ideas de una minoría puedan «ofender, consternar o perturbar» a la mayoría y generar una oposición violenta no puede justificar una prohibición general a la expresión de las opiniones de dicha minoría por medio de reuniones pacíficas. Al contrario, el Estado debería proteger las reuniones pacíficas de los grupos minoritarios contra este tipo de actos violentos.» (párrafo 3). La autoridad rusa no comparte el criterio y deniega el permiso. El caso parecía visto para sentencia, y nunca mejor dicho, dado que el 1 de noviembre de 2010 el autor informó de que, el 21 de octubre de ese mismo año, el TEDH había fallado sobre su causa, sobre la negativa de las autoridades a autorizar la celebración de actos similares a los mencionados en la presente comunicación, en 2006, 2007 y 2008. En ese caso concreto, el TEDH estableció que se habían violado los derechos del autor conforme a lo establecido en el artículo $11 \mathrm{CEDH}$ (libertad de reunión pacífica ${ }^{45}$.

El Comité decide que el caso resulta admisible porque en el de autos se dan circunstancias objetivas diferentes, impugnándose ahora la prohibición de celebrar un piquete en protesta por la ejecución de homosexuales y menores en la República Islámica del Irán (párrafo 8.2).

Posteriormente, se pronuncia sobre el fondo del asunto. Y en un razonamiento ya conocido dirá que «El Comité señala que el permiso para celebrar el piquete propuesto por el autor se negó exclusivamente porque, dado el tema que trataba (la promoción del respeto de los derechos humanos de las personas pertenecientes a minorías sexuales), habría provocado una reacción negativa que habría podido llevar a alteraciones del orden público. Al

${ }^{44}$ Por el contrario, en uno de los últimos casos de los que se ha tenido noticia (W.K. c. Canadá, Dictamen de 27 de marzo de 2018, referencia CCPR/C/122/D/2292/2013), el Comité decide de forma diametralmente opuesta por estimar que el actor no funda lo suficiente su alegación respecto de la «peligrosidad» de su extradición de Canadá a Egipto.

45 Vid. GILBAJA CABRERO, Estela: «Orientación...», cit; p. 329. 
denegarse el permiso no se mencionaron ni el lugar, ni la fecha, ni la duración ni la forma propuestos para la celebración de la reunión. Por tanto, en la decisión del subprefecto del Distrito Administrativo Central de Moscú de 11 de julio de 2008 se negó el derecho del autor a organizar una reunión pública por girar en torno a un tema concreto, lo cual supone una de las injerencias más graves que pueden concebirse con respecto al derecho a la libertad de reunión pacífica. El Comité señala que la libertad de reunión protege a las manifestaciones que promuevan ideas que otras personas pueden considerar molestas u ofensivas y que, en esos casos, los Estados partes tienen la obligación de proteger a quienes participan en ellas en ejercicio de sus derechos de los actos violentos cometidos por terceros. Señala además que la existencia de un peligro general y no especificado de que haya una contramanifestación violenta o la mera posibilidad de que las autoridades no puedan evitar o neutralizar la violencia no bastan para prohibir una manifestación. El Estado parte no ha facilitado al Comité ninguna información en el presente caso que pueda fundamentar su afirmación acerca de la posibilidad de una «reacción negativa» de otros miembros de la opinión pública al piquete propuesto por el autor, que la policía no habría sido capaz de impedir en el adecuado desempeño de su mandato. En tales circunstancias, la obligación del Estado parte era proteger los derechos que el Pacto confiere al autor, no contribuir a suprimirlos. Por este motivo, el Comité concluye que la restricción de los derechos del autor era innecesaria en una sociedad democrática para proteger la seguridad pública, y que vulneró el artículo 21 del Pacto» (párrafo 9.6). Y condena a Rusia al pago de una indemnización adecuada y al resarcimiento de gastos y costas procesales.

En dicho año, 2013, también se ventiló el caso M.I. c. Suecia (Dictamen de 25 de julio de 2013, referencia CCPR/C/108/D/2149/2012). El caso es muy similar al estudiado arriba, M.Z.B.H c. Dinamarca, solo que ahora el procedimiento de asilo se sigue en Suecia. Y el Comité da la razón a la autora, quien nunca escondió su condición de lesbiana, condición por la que sufrió violaciones reiteradas, malos tratos policiales y persecución por parte de organizaciones estudiantiles islámicas en Bangladesh. Lo hace partiendo de la base que «los homosexuales son estigmatizados en la sociedad de Bangladesh». El Comité considera que «la existencia de esa legislación fomenta de por sí la estigmatización de las personas lesbianas, gays, bisexuales y transexuales y constituye un obstáculo a la investigación y el castigo de los actos de persecución contra estas personas. El Comité considera que, al decidir sobre su solicitud de asilo, las autoridades del Estado parte se centraron principalmente en las incoherencias y ambigüedades en la exposición de hechos específicos que efectuó la autora. Sin embargo, las incoherencias y ambigüedades mencionadas no son de naturaleza tal como para restar verosimilitud a los riesgos temidos. Habida cuenta de la situación a que se enfrentan las 
personas pertenecientes a minorías sexuales, de la que se da cuenta en los informes presentados por las partes, el Comité opina que, en el caso particular de la autora, el Estado parte no tomó debidamente en consideración las alegaciones de la autora sobre lo que le ocurrió en Bangladesh a causa de su orientación sexual, en particular los malos tratos sufridos a manos de la policía, al evaluar el supuesto riesgo que correría si regresara a su país de origen. Por consiguiente, en tales circunstancias, el Comité considera que la expulsión de la autora a Bangladesh constituiría una vulneración del artículo 7 del Pacto» (párrafo 7).

\subsection{Comité contra la Tortura}

En esta materia destacan dos asuntos, uno de 2017 y otro de 2015. El primero es el caso E.A. c. Suecia; el segundo es el caso J.K. c. Canadá.

En el caso E.A. c. Suecia (Dictamen de 11 de agosto de 2017, referencia $\mathrm{CAT} / \mathrm{C} / 61 / \mathrm{D} / 690 / 2015)$, se plantea un caso bastante similar al anterior. El litigante acude al Comité para solicitar que no sea devuelto por las autoridades suecas al Líbano, toda vez que su condición de homosexual declarado le reportaría diferentes malos tratos y vejaciones por parte de las autoridades libanesas, especialmente por parte de sus cuerpos y fuerzas del orden. El Comité aplica un test conocido para solventar estos casos y que podríamos resumir en una directriz: incluso aunque estemos en condiciones de afirmar que el país en cuestión viola masivamente los derechos humanos, el actor soporta la carga de la prueba de que en su caso particular el riesgo de sufrir torturas y/o malos tratos es cierto y probable, concreta e individualmente. De lograrlo, tendría derecho al non-refoulement que la Convención le reconoce. El Comité, en una decisión cuestionable, estima que «las alegaciones del autor de que correría un riesgo personal de sufrir un trato contrario al artículo 3 de la Convención son hipotéticas y no van más allá de la pura teoría o sospecha. El Comité concluye que el autor no ha satisfecho la carga de presentar un caso defendible» (párrafo 9.7). Y por ello, «considera que este no ha aportado pruebas suficientes que le permitan llegar a la conclusión de que la expulsión por la fuerza a su país de origen lo expondría a un riesgo previsible, real y personal de tortura en el sentido del artículo 3 de la Convención» (párrafo 10), lo cual le lleva a considerar que expulsión no vulnera dicho artículo (párrafo 11).

En el caso J.K. c. Canadá (Dictamen de 23 de noviembre de 2015, referencia CAT/C/56/D/562/2013) estamos ante un supuesto muy similar aunque con desenlace diferente. El país al que va a ser devuelto el litigante es Uganda, quien alega que de ser extraditado por Canadá se haría en lesión del artículo 3 de la Convención. Es notorio y sabido que la Uganda oficial es un país abiertamente homófobo y así lo hace constar el Comité. Por ejemplo, 
dice este que: «El Comité observa que el Estado parte ha reconocido que la situación del colectivo de personas lesbianas, gays, bisexuales, transgénero e intersexuales en Uganda es problemática y ha empeorado a raíz de la promulgación de la Ley contra la Homosexualidad. El Comité observa también que, a pesar de que esa Ley fue declarada nula por el Tribunal Constitucional en agosto de 2014, el Tribunal basó su decisión en una cuestión de procedimiento (el hecho de que fuese aprobada sin el quórum necesario) y la Ley podría volver a ser presentada en el Parlamento en cualquier momento. El Comité observa, asimismo, que según informaciones de dominio público, tras la promulgación de la Ley, hubo un incremento de los casos de detención arbitraria, extorsión por la policía, desalojo y atentado contra la reputación de las personas lesbianas, gais, bisexuales, transgénero e intersexuales, así como del número de esas personas que se quedaron sin techo. Además, el Comité observa que hay informes que indican que algunas personas lesbianas, gais, bisexuales, transgénero e intersexuales han sido golpeadas y vejadas por la policía y por los reclusos cuando se encontraban bajo custodia. Así pues, el Comité considera que el autor podría correr el riesgo de sufrir tortura o malos tratos si fuese devuelto a Uganda teniendo en cuenta no solo su orientación sexual, sino también su militancia en organizaciones de personas lesbianas, gais, bisexuales, transgénero e intersexuales y el hecho de que podría ser detenido para responder de los cargos penales que se han presentado contra él» (párrafo 10.5). Por ello declara que la devolución del actor en estas circunstancias vulneraría el artículo 3 de la Convención.

\section{Protección desde otros órganos}

Dentro de los restantes mecanismos de protección que la ONU prevé es de justicia hacer una referencia, por somera que sea, a dos instituciones capitales: el Alto Comisionado para los Derechos Humanos y la Secretaría General.

\subsection{El Alto Comisionado de las Naciones Unidas para los Derechos Humanos}

Además de lo que se dijo arriba, destacan al menos tres hitos más protagonizados por el Alto Comisionado de las Naciones Unidas para los Derechos Humanos.

El primero es el Informe sobre prácticas discriminatorias y actos de violencia cometidos contra personas por su orientación sexual e identidad de género, presentado al Consejo de Derechos Humanos en $2015^{46}$. En él destaca que «Si bien se han hecho algunos progresos desde el primer estudio, llevado

${ }^{46}$ Disponible en: http://www.ohchr.org/EN/Issues/Discrimination/Pages/LGBTUNReports.aspx (consultado el 16 de enero de 2019). 
a cabo en 2011, en general las personas LGBT e intersexuales siguen viéndose afectadas por un cuadro extendido y persistente de malos tratos violentos, acoso y discriminación en todas las regiones. Estos actos constituyen violaciones graves de los derechos humanos, perpetrados a menudo con impunidad, lo que indica que las disposiciones vigentes para proteger los derechos humanos de las personas LGBT e intersexuales son inadecuadas. Al día de hoy no existe un mecanismo especializado de derechos humanos a nivel internacional que aplique un enfoque sistemático e integral de la situación de los derechos humanos de las personas LGBT e intersexuales». En el mismo año 2015 tuvo lugar el segundo hito. El ACNUDH celebró una Reunión de Expertos para poner fin a la discriminación de las personas intersexuales, aprobándose finalmente la Ficha de Datos sobre los derechos humanos de las personas intersexuales ${ }^{47}$. Dicho documento destaca, y creo que con razón, los casos pioneros y punteros de Australia y Malta. Los aussies aprobaron, en 2013, la Enmienda de la Ley sobre la Discriminación Sexual (Orientación sexual, identidad de género e intersexualidad), la primera ley que incluye el estatus intersexual como un motivo prohibido de discriminación per se, en sí mismo. El Senado de Australia también ha llevado a cabo una investigación oficial sobre la esterilización forzada o involuntaria de las personas intersexuales. Por su parte, Malta aprobó en 2015 la Ley sobre Identidad de Género, Expresión de Género y Caracteres Sexuales, la primera disposición legislativa que prohíbe la cirugía y el tratamiento de los caracteres sexuales de los menores sin consentimiento informado. Asimismo, prohíbe la discriminación basada «en los caracteres del sexo». Son buenas muestras de que cuando los Estados quieren, pueden. El tercer hito llega en 2016, cuando el ACNUDH publicó el exhaustivo Vivir Libres e Iguales: Qué están haciendo los Estados para abordar la violencia y discriminación contra las personas lesbianas, gays, bisexuales, transgénero e interse $x^{48}$, un Informe que se ha convertido (o debería) en una auténtica referencia en la materia. Por la extensión y abundancia de datos, nos quedamos aquí con su principal conclusión: da cuenta de que en los últimos tiempos diversas autoridades a lo largo y ancho del planeta han adoptado medidas de «gran alcance» para tratar las violaciones de derechos humanos contra las personas LGBTI, haciéndose eco de más de doscientas medidas en sesenta y cinco países diferentes ${ }^{49}$.

47 Se han leído aquí: www.ohchr.org/EN/NewsEvents/Pages/Astepforwardforintersexvisibility.aspx y aquí: www.ohchr.org/EN/Issues/Discrimination/Pages/LGBTFactSheets.aspx (consultado el 16 de enero de 2019).

48 Se ha leído aquí: https://www.ohchr.org/Documents/Publications/LivingFreeAndEqual_SP.pdf (consultado el 16 de enero de 2019).

49 Ejemplos concretos: Argentina garantiza el derecho de acceder a los llamados «tratamientos de afirmación de género», mientras que Nueva Zelanda o Dinamarca permiten que su ciudadanía elija la «X» en documentos oficiales como el Pasaporte (garantizando 


\subsection{Secretaría General}

Desde la Secretaría General de Naciones Unidas se han acometido acciones relevantes ${ }^{50}$. En el año 2014, Ban Ki-moon, el que todavía es en la actualidad Secretario General, publicó un mensaje con ocasión del Día Internacional contra la Homofobia y la Transfobia, el 16 de mayo de 2014, donde defendía que los derechos de las personas LGTB son derechos humanos y que los derechos humanos son derechos de las personas LGTB. Y que estas personas gozan del derecho a vivir sus vidas sin discriminación de ningún tipo y de obtener de poderes públicos y particulares un trato igual, garantizando que conduzcan sus vidas en libertad ${ }^{51}$.

El Secretario General no deja de lamentar la realidad que, incluso a día de hoy, se observa en muchos (demasiados) Estados, donde se tipifican como delito conductas sexuales que califican de «desviadas», y donde se cometen todo tipo de tropelías contra personas LGTBI, desde malos tratos y torturas, hasta acoso en las calles, escuelas y trabajos; desde las llamadas «violaciones correctivas» hasta los más viles asesinatos (en demasiadas ocasiones cerrados sin apenas investigación). El Secretario General ha seguido en la brecha, impulsando y defendiendo los derechos de las personas LGTBI con apoyo

el género no binario). Por otro lado, algunos Estados han tomado medidas para reducir el abuso hacia los adultos y niños LGBT e intersexuales en el entorno médico (por ejemplo, Suiza e Irlanda), incluyendo la erradicación de las llamadas terapias de «conversión» y la esterilización forzada (cosa que ha sucedido en Estados Unidos, China y Ecuador, cerrando centros donde se llevaban a cabo). Otros Estados han eliminando las clasificaciones médicas que asumían que la transexualidad era una patología (Sudáfrica). Dos Estados han prohibido la discriminación por motivo de caracteres sexuales/condición intersexual (Australia y Sudáfrica) y otro más ha prohibido las cirugías innecesarias realizadas a los niños intersexuales (Argentina). Diferentes resoluciones judiciales han defendido los derechos de las organizaciones LGTBI tanto pare registrarse como para llevar a cabo las actividades que les son propias, amén de reconocer indemnizaciones a causa de las violaciones de sus derechos (Tailandia, Malasia, o Lituania). Se han dictado diversas ordenanzas locales para perseguir delitos motivados por el odio, y se han llevado acciones de capacitación de funcionarios locales, así como diversas iniciativas educativas (Filipinas, México, Alemania, Argentina, Rusia, Brasil, y Malta). Vid. ALTO COMISIONADO DE NACIONES UNIDAS PARA LOS DERECHOS HUMANOS: Vivir Libres e Iguales. Organización de Naciones Unidas, Ginebra, 2016, pp. 141 y ss.

${ }^{50}$ Vid. JIMÉNEZ RUIZ, José Luis; y MARTÍN CÁCERES, L; «Juicios de Sodoma: argumentos y crónica jurídica». En Revista Aranzadi Doctrinal 2 (2016), p. 226. A pesar de esto, el Secretario General suele ser criticado por su débil apoyo («soft-peddling»). Vid. ALSTON, Philip; y GOODMAN, Ryan; International..., cit, p. 228.

${ }^{51}$ La transcripción completa puede verse aquí: http://www.un.org/es/sg/messages/2014/homoday2014.shtml\# (consultado el 5 de noviembre de 2018). Incluso defendió el mensaje en público estando en Rusia, ante una nutrida representación diplomática universal con motivo de los Juegos de Invierno de Sochi de 2014. Vid. https://www.youtube. com/watch?v=If7pvU-HFkI (consultado el 16 de enero de 2019). 
explícito a diversas iniciativas, encuentros y conferencias a nivel regional y mundial ${ }^{52}$.

\section{UN BALANCE CRÍTICO}

Es ahora donde debemos interrogarnos sobre lo que se ha hecho y sobre lo que queda por hacer.

\section{Sobre lo que se ha hecho}

En líneas generales, la ONU ha seguido trabajando en pos de lograr que las personas LGTBI puedan disfrutar de los derechos humanos libres de trazas discriminatorias. No puede decirse que se haya quedado cruzada de brazos. Ha reforzado algunos mecanismos existentes, y ha creado otros nuevos tales como el Experto Independiente. Además, los mecanismos de protección convencionales han ventilado casos a favor de las personas LGTBI cuando han estimado que en Derecho así debía hacerse. La dignidad, la libertad y la igualdad (especialmente en su vertiente de no discriminación) suelen ser los principales valores en los que se basan, cosa que por lo demás es bastante común en el razonamiento jurídico comparado cuando de derechos LGTBI se trata ${ }^{53}$. Por todo ello el balance es en líneas generales positivo ${ }^{54}$.

No obstante, existen todavía algunas cuestiones pendientes. Diversos sectores doctrinales destacan que por más que estemos en 2018 no existe consenso internacional para crear una norma jurídica vinculante, un auténtico tratado internacional, en la materia. Los avances se producen a golpe de jurisprudencia. Los Comités realizan una tarea encomiable, pero su eficacia real tiene mucho que ver con eso que Pastor Ridruejo denomina la «movilización de la vergüenza», con órganos decisores más políticos que jurídicos y con mucho de convencimiento previo de los diferentes Estado para cumplir (o incumplir) los preceptos correspondientes ${ }^{55}$. Para bien o

52 Así lo hizo, por ejemplo, saludando la «Global LGBTI Human Rights Conference», celebrada en Montevideo, Uruguay, en el año 2016, declarando «estar orgulloso de formar parte de quienes luchan contra la discriminación contra las personas LGTBI». Vid. https://www.youtube.com/watch?v=yATlpSYXtiw (consultado el 16 de enero de 2019).

${ }_{53}$ Vid. SPERTI, Angioletta: Constitutional Courts, Gay rights and sexual orientation equality. Hart Publishing, London, 2017, p. 196.

${ }^{54}$ Vid. PIOVESAN, Flavia; y KAMIMURA, Akemi: «Proteção internacional à diversidade sexual e combate à violência e discriminação baseadas a orientação sexual e identidade de gênero». En Anuario de Derecho Público 1 (2017), pp. 173-190.

55 Vid. PASTOR RIDRUEJO, José Antonio: «La globalización de los derechos humanos: El reto del siglo XXI». En Revista Europea de Derechos Fundamentales 2 (2003), pp. 19-34; y PASTOR RIDRUEJO, José Antonio: «Prólogo». En Ochoa Ruiz, Natalia: 
para mal, el margen de apreciación de los Estados en estas cuestiones sigue siendo amplio ${ }^{56}$.

Como posibles alternativas, quizá se podría intentar introducir cláusulas específicas contra la discriminación por orientación sexual e identidad de género en los diferentes Convenios, aunque precisamente la falta de consenso internacional sobre estos asuntos a buen seguro daría al traste con la iniciativa ${ }^{57}$. A lo mejor esa idea recurrente de crear un Tribunal Internacional en Naciones Unidas pueda ayudar a estas personas a ver realmente garantizados sus derechos. El problema que se barrunta aquí es doble: no sólo es más que probable que persista la falta de consenso en su creación; es que incluso se consiguiera, es muy posible que este muriera de éxito ante la potencial avalancha de demandas ${ }^{58}$.

\section{Prospectiva de futuro}

Para conseguir crear una cierta cultura de respeto a los derechos humanos allá donde la hay solo de modo muy precario, se puede acudir al auxilio de

Los mecanismos convencionales de protección de los derechos humanos en Naciones Unidas. Civitas, Madrid, 2004, pp. 24 y ss.

${ }^{56}$ Lo que habría que fortalecer en el orden internacional no es, pues, el poder de los Estados, que ya tienen y en abundancia. Lo que se debe fortalecer es aquello que Ferrajoli define como instituciones de garantía, tanto las primarias (aquellas que verifican la paz y la seguridad entre Estados), como las secundarias (aquellas que garantizan esa ley del más débil que son los derechos fundamentales mediante instituciones jurisdiccionales). La falta de unas y otras es la triste realidad actual, a juicio del jurista italiano. Vid. FERRAJOLI, Luigi: Constitucionalismo más allá del Estado. Trotta, Madrid, 2018, p. 41 y ss.

${ }^{57}$ Hay algunos autores que creen, por el contrario, que es mejor mantener el listado de derechos humanos razonablemente corto y cuya redacción sea abstracta (que no ambigua). El motivo sería poder crear una «meseta egalitaria», un mínimo común denominador sobre el cual debatir respecto a los desacuerdos que surjan. Vid. LUKES, S; «Cinco fábulas sobre los derechos humanos». En Shute, Stephen; y Hurley, Susan (eds); De los derechos humanos. Trotta, Madrid, 1998, p. 46.

${ }_{58}$ Así lo asevera PASTOR RIDRUEJO, José Antonio; «La globalización...», cit, quien considera la idea «absolutamente inviable» (p. 32), defendiendo por el contrario la subsidiariedad: «hacer caer la carga de creación de mecanismos de control en los Estados» (p. 33). Sobre la creación de ese Tribunal Internacional puede verse RODLEY, Nigel S; «The role...». En Shelton, David (ed); The Oxford..., cit, p. 647; y, especialmente, la tesis de NOWAK, M; «La necesidad de un tribunal mundial». En Almqvist, Jessica; y Gómez Isa, Felipe (coords.); El Consejo de Derechos Humanos. Oportunidades y Desafios. Universidad de Deusto, Bilbao, 2006, pp. 57-66, donde apuesta por crear un nuevo Tratado en el marco de la ONU («Estatuto del Tribunal»), sin afectar a la Carta y/o al resto de Tratados, y con membresía tanto de Estados como de agentes no estatales. 
algunas ideas doctrinales, ideas que se están desarrollando en un debate mucho más amplio que aquí sólo podemos apuntar ${ }^{59}$.

Un primer ejemplo sería la idea de Liborio Hierro. Para el iusfilósofo, las personas tenemos el derecho moral básico a vivir en un cierto tipo de Estado, a lo que se une la necesidad de un poder coercitivo para garantizar que los Estados son Estados de ese tipo. Es decir, un Estado que garantice la seguridad, la libertad, y la igualdad, que reconozca cierto orden social e internacional en el

${ }_{59}$ En lo que hace a los derechos fundamentales parece que en la actualidad pugnan dos paradigmas. El paradigma sólido, que defiende una interpretación literal de las normas, especialmente las constitucionales, en aras de garantizar la normatividad de las mismas así como la seguridad jurídica y la previsibilidad (sólo son derechos fundamentales los derechos positivados en la Constitución y en los términos que determine). Y el paradigma líquido, metáfora bien conocida y auspiciada por Zygmunt Bauman que llega al mundo del Derecho, haciendo ahora que los derechos fundamentales sean también aquellos resultantes de la interpretación que los altos tribunales hagan en el marco de un fluido diálogo entre ellos (para el caso español tal extremo lo ejemplificaría, por poner un ejemplo, la STC 198/2012, que reconoce el derecho al matrimonio de las personas homosexuales haciendo decir al artículo $32 \mathrm{CE}$ lo que este en su literalidad no dice). Un representante del primer sector, muy crítico con las tesis del segundo, es VILLAVERDE MENÉNDEZ, Ignacio: «El constitucionalismo líquido. La dogmática constitucional de los derechos fundamentales del siglo XXI tras 40 años de Constitución Española de 1978». En Punset Blanco, Ramón (coord.); Álvarez Álvarez, Leonardo (coord.); y Roca Martínez, José María (pr): Cuatro decadas de una Constitución normativa (1978-2018): Estudios sobre el desarrollo de la Constitución Española. Thomson Reuters-Civitas, Cizur Menor, 2018, pp. 31-51. También se puede consultar MATIA PORTILLA, Francisco Javier: «De primacía, derechos y tribunales», en GORDILLO PÉREZ, Luis (coord.): Constitución española e integración europea. Treinta años de Derecho Constitucional de la integración. Valencia, Tirant lo Blanch, 2018; específicamente sobre la resolución referida, puede verse MATIA PORTILLA, Francisco Javier: «Interpretación evolutiva de la Constitución y legitimidad del matrimonio formado por personas del mismo sexo». En Teoría y Realidad Constitucional 31 (2013), pp. 541-554. Para conocer a fondo el segundo paradigma puede leerse el trabajo de BUSTOS GISBERT, Rafael: «XV proposiciones generales para una teoría de los diálogos judiciales». En Revista Española de Derecho Constitucional 95 (2012), pp. 13-63; el de GARCÍA ROCA, Javier: «El diálogo entre el Tribunal Europeo de Derechos Humanos y los tribunales constitucionales en la construcción de un orden público europeo». En Teoría y Realidad Constitucional 30 (2012), pp. 183-224; el de LÓPEZ GUERRA, Luis: «El diálogo entre el Tribunal Europeo de Derechos Humanos y los tribunales españoles. Coincidencias y divergencias». En Teoría y Realidad Constitucional 32 (2013) pp. 139-158; el de XIOL RIOS, Juan Antonio: «El diálogo entre Tribunales», en ASOCIACIÓN DE LETRADOS DEL TRIBUNAL CONSTITUCIONAL, Tribunal Constitucional y diálogo entre tribunales, Madrid, CEPC, 2013, pp. 1156; y el de SAIZ ARNAIZ, Alejandro: «Tribunal Constitucional y Tribunal Europeo de Derechos Humanos: las razones para el dialogo». En ASOCIACIÓN DE LETRADOS DEL TRIBUNAL CONSTITUCIONAL: Tribunal Constitucional y diálogo entre tribunales. CEPC, Madrid, 2013, pp. 131-160. 
que los derechos y libertades proclamados en la DUDH se hagan efectivos (que es en definitiva lo que reconoce su artículo 28$)^{60}$.

Para ello debemos tener en cuenta algunas resistencias podríamos decir que estructurales. John Rawls dejó algunas reflexiones al hilo de la Guerra de los Balcanes que siguen teniendo vigencia. Recordaba el jurista que hay Estados «proscritos», que lo querrán seguir siendo porque no cejarán en su empeño de reprimir casi cualquier conducta que huela a libertad. A este tipo de Estados no basta con decirles alto y claro que hay líneas rojas en forma de derechos humanos, sino que hay que negarles todo tipo de ayuda (económica, política, militar, y de cualquier otra índole). También habría Estados «con condiciones desfavorables», pero a diferencia de aquéllos, a estos sí que habría que ayudarles en el objetivo de alcanzar una sociedad bien ordenada, enfatizando la idea de derechos humanos junto a una batería de medidas adicionales que moderen lentamente la opresión de las minorías ${ }^{61}$.

Si con esto no resulta, a lo mejor se puede dar entrada a la propuesta de Richard Rorty. Para el filósofo estadounidense el problema de la gente mala no es que sea «menos racional», «menos lúcida», o «más prejuiciosa». El problema es que son desposeídos, en concreto de seguridad y de simpatía. Él lo razona así: «cuanto más duras son las cosas o más miedo se siente o más peligro se experimenta, menos tiempo y esfuerzo puede dedicarse a pensar en la condición de las personas con las cuales no te identificas de inmediato. La educación sentimental funciona únicamente cuando las personas pueden relajarse lo suficiente como para escuchar». Dicho con otras palabras, siempre las suyas: «la difusión de la cultura de los derechos humanos responde mucho más a un progreso de los sentimientos más que a la moral», habiéndose «vuelto para nosotros mucho más fácil movernos a actuar gracias a las historias tristes y sentimentales $\rangle^{62}$. ¿Cómo llegar a sus corazones? ¿Cómo conseguir hacer de ello un arma política para el bien? Difícil, aunque ilusionante tarea.

Voces autorizadas nos recuerdan que la clave residirá en la gestión de las notables -y cada vez mayores- diferencias existentes entre las comunidades

${ }^{60}$ HIERRO, Liborio: Los derechos humanos. Una concepción de la justicia. Marcial Pons, Madrid, 2016, p. 258. El artículo 28 de la DUDH es un precepto realmente potente. Reza así: «Toda persona tiene derecho a que se establezca un orden social e internacional en el que los derechos y libertades proclamados en esta Declaración se hagan plenamente efectivos».

${ }^{61}$ Vid. RAWLS, John: «Derecho de gentes». En Shute, Stephen; y Hurley, Susan (eds); De los derechos humanos. Trotta, Madrid, 1998, pp. 47-85.

${ }_{62}$ Vid. RORTY, Richard: «Derechos humanos: racionalidad y sentimentalidad». En Shute, Stephen; y Hurley, Susan (eds); De los derechos humanos. Trotta, Madrid, 1998, pp. 131 y ss. 
jurídico-políticas ${ }^{63}$. Por un lado tenemos a los Estados occidentales, que no han hecho sino intentar dar cabida a las reivindicaciones de las personas LGTBI a medida que sus demandas han entrado en el sistema. De otro lado tenemos el conjunto de Estados que hacen todo lo contrario. Y entre medias, una amplia panoplia donde cunden ejemplos de todo tipo. Las velocidades y las exigencias son diferentes. Los que iniciaron la carrera en pos de la igualdad y no discriminación hace muchos años ahora tienen que decidir entre algunas disyuntivas de calado (¿teoría posmoderna que vuela los cimientos del proyecto racional e ilustrado o mejora de este mediante el refuerzo de la igualdad y no discriminación del catálogo de derechos para todos? ${ }^{64}$. Pero esas disyuntivas no se parecen en nada a las que encaran quienes viven todavía en sociedades con aromas a estado de naturaleza, sin rastro de Estado de Derecho, de Constitución, o de democracia ${ }^{65}$.

\section{CONCLUSIONES}

Partiendo de la base de que el orden internacional es testigo tantos de avances como de retrocesos en los derechos de las personas LGTBI, en líneas anteriores hemos estudiado qué y cómo ha abordado en estos últimos cuatro

${ }^{63}$ Resulta especialmente sugerente la investigación de la que da cuenta IGNATIEFF, Michael: Las virtudes cotidianas. El orden moral en un mundo dividido. Taurus, Madrid, 2018. En ella sostiene que se pone de manifiesto un claro «descontento con la globalización que hace que las personas defiendan su identidad» (p. 257); que «puesto que la globalización está poniendo en entredicho tantas fuentes de autoridad moral, sorprende que los activistas internacionales de derechos humanos den la suya por sentada» (p. 261); y que «la soberanía democrática y el universalismo de los derechos humanos va camino del enfrentamiento en todas partes» (p. 262).

${ }^{64}$ Plantea la disyuntiva (decantándose por la segunda opción) MONEREO ATIENZA, C; Diversidad..., cit, p. 10 y ss. Se ha encontrado una brillante contribución sobre el trasfondo intelectual general de debates como este en OVEJERO, Félix: La deriva reaccionaria de la izquierda. Página Indómita, Madrid, 2018 (especialmente en su «Introducción», pp. 21-76; y en «La Izquierda Posmoderna», pp. 111-124.). También puede resultar interesante al lector la tesis que defiende BERNABE, Daniel: La trampa de la diversidad. Akal, Madrid, 2018 ( $6^{\mathrm{a}}$ edición).

${ }_{65}$ Aunque a día de hoy el planteamiento de fondo de filósofos como Zizek se antoja bastante trasnochado («la lucha comunista por la emancipación universal», tal y como él la llama, p. 294), tiene algunas reflexiones que merece la pena rescatar. Por ejemplo, que la defensa anticolonialista multicultural de la multiplicidad de modos de vida es falsa, porque oculta y justifica actos de brutalidad, sexismo y racismo que dejamos correr por no caer en «mentalidades imperialistas». Por ello en ningún caso se debería suscribir un compromiso estratégico que tolere en silencio costumbres que humillan a personas homosexuales, so pretexto de que forman parte de una lucha «más amplia». Vid. ZIZEK, Slavoj: El coraje..., cit, pp. 293 y 294. 
años la promoción y protección de los mismos la Organización de Naciones Unidas.

Desde la perspectiva de los mecanismos basados en la Carta destaca la labor del Consejo de Derechos Humanos, especialmente mediante dos instrumentos. En primer lugar, el Examen Periódico Universal, realizado bajo los auspicios del primero, y que ha otorgado cierto realce a la no discriminación de las personas LGTBI. En segundo lugar, mediante la creación de la que es la principal y auténtica novedad en la materia, el Experto Independiente en Orientación Sexual e Identidad de Género, quien ya ha llevado a cabo algunas acciones meritorias que el tiempo dirá si tienen o no continuidad. En líneas generales puede hablarse de una importante promoción, pero no tanto protección, en la medida en que no estamos ante órganos con competencia para dictar resoluciones jurídicamente vinculantes.

Desde la perspectiva de los mecanismos basados en el Derecho Internacional de los Derechos Humanos, destacan los casos que han llegado al Comité de Derechos Humanos y al Comité contra la Tortura. El primero ha decidido seis casos y el segundo dos. En seis de los ocho se dio la razón al litigante, que era con carácter general una persona LGTBI. Aquí se puede hablar más de protección que de mera promoción, aunque es cierto que la propia idiosincrasia de este tipo de órganos no permite lanzar las campanas al vuelo. Algo más de protección, pues, ma non troppo.

Desde la perspectiva de otros órganos de la ONU, destaca con mucho la ingente labor del ACNUDH, llevando a cabo una encomiable tarea de estudio, informe y difusión de los derechos humanos de las personas LGTBI por todo el globo. También destaca el papel, formal y diplomático pero real y sincero, de la Secretaría General, con mensajes institucionales de apoyo y aliento a la causa.

Finalmente, se ha realizado un balance de urgencia y una modesta prospectiva de futuro, con ideas generales sobre por dónde podrían discurrir futuros derroteros sobre la base de un balance general. En ese sentido, la tensión que late en el fondo del problema es casi idéntica a la que late en el fondo de buena parte de problemas que presenta el ordenamiento internacional: la convicción y voluntad de los Estados, auténtica clave de bóveda para el trato humano y justo de las personas LGTBI. Si desde los Estados se llama a «curarles», cuando no a «perseguirles», a «expulsarles» o, incluso, «matarles», poco se podrá hacer más allá de seguir reivindicando su libertad e igualdad con todas las armas de las que disponen las democracias constitucionales.

\section{BIBLIOGRAFÍA}

AlmQvist, J. «El Consejo de Derechos Humanos: un paso audaz hacia derechos efectivos para todos». En Almqvist, Jessica; y Gómez Isa, Felipe (coords.): El 
Consejo de Derechos Humanos. Oportunidades y Desafios. Universidad de Deusto, Bilbao, 2006, pp. 37-46.

Alston, P.; y Goodman, R. International Human Rights. Oxford University Press, Oxford, 2013.

Alto Comisionado de Naciones Unidas para los Derechos Humanos. Vivir Libres e Iguales. Organización de Naciones Unidas, Ginebra, 2016.

Álvarez Rodríguez, I. «La Organización de las Naciones Unidas y el derecho a la no discriminación por motivo de orientación sexual e identidad de género: apuntes para un debate», Revista General de Derecho Constitucional 17 (2013), pp. 1-30.

Alventosa Del Río, J. «Derechos humanos y orientación sexual e identidad de género». En Rey Martínez, Fernando (dir).: Los derechos humanos en España: un balance crítico. Tirant lo blanch, Valencia, 2015, pp. 736-781.

AMNISTía INTERNACIONAL. Informe 2017-2018. La situación de los derechos humanos en el mundo. Londres, 2018.

BernabÉ, D. La trampa de la diversidad. Akal, Madrid, 2018 (6 edición).

Bilbao Ubillos, J. M.; y Moretón Toquero, M. A. «Protección de los derechos humanos en España. Marco normativo». En Rey Martínez, Fernando (dir).: Los derechos humanos en España: un balance critico. Tirant lo blanch, Valencia, 2015, pp. 29-33.

Bustos GISBERT, R. «XV proposiciones generales para una teoría de los diálogos judiciales». En Revista Española de Derecho Constitucional 95 (2012), pp. 13-63.

Carozza, P. «Human Dignity». En Shelton, David (ed.); The Oxford Handbook of International Human Rights Law. Oxford University Press, Oxford, 2013, pp. 345-359.

Carroll, A.; y Mendos, L. R.: Homofobia de Estado, ILGA, 2017 (12 edición).

ClifFord, J. «Equality». En Shelton, David (ed.); The Oxford Handbook of International Human Rights Law, Oxford University Press, Oxford, 2013, pp. 420-445.

Díaz LAFUente, J. Asilo y refugio por motivos de orientación sexual e identidad de género. Congreso de los Diputados, Madrid, 2016.

—El derecho a la igualdad y a la no discriminación por motivos de orientación sexual». En Cuesta López, Víctor Manuel; y Santana Vega, Dulce María (coords.); Estado de Derecho y discriminación por razón de género, orientación e identidad sexual. Thomson Reuters, Cizur Menor, 2014.

Fernández Liesa, C. El Derecho Internacional de los Derechos Humanos en perspectiva histórica. Aranzadi, Cizur Menor, 2013.

Ferrajoli, L. Constitucionalismo más allá del Estado. Trotta, Madrid, 2018.

GarCía RocA, J. «El diálogo entre el Tribunal Europeo de Derechos Humanos y los tribunales constitucionales en la construcción de un orden público europeo». En Teoría y Realidad Constitucional 30 (2012), pp. 183-224.

Gartenberg, M. (dir.); y Blank, E. (codir.); United Nations Human Rights Council. Protection of LGTB Youth, CJMUNG, 2018.

Gilbaja CABrero, E. «Orientación sexual y Tribunal Europeo de Derechos Humanos». En Revista de Derecho Político 91 (2014), pp. 303-340.

Hellum, A. (ed): Human Rights, Sexual Orientation and Gender Identity. Routledge, Oxon-New York, 2017. 
Hierro, L. Los derechos humanos. Una concepción de la justicia. Marcial Pons, Madrid, 2016.

IGNATIEFF, M. Las virtudes cotidianas. El orden moral en un mundo dividido. Taurus, Madrid, 2018.

JimÉneZ Ruiz, J. L.; y MARTín CÁCERES, L. «Juicios de Sodoma: argumentos y crónica jurídica». En Revista Aranzadi Doctrinal (2) 2016, pp. 223-246.

KothaRI, M. «From Comission to the Council: Evolution of UN Charter Bodies». En Shelton, David (ed.); The Oxford Handbook of International Human Rights Law. Oxford University Press, Oxford, 2013, pp. 587-620.

LÓPEz GuerRA, L. «El diálogo entre el Tribunal Europeo de Derechos Humanos y los tribunales españoles. Coincidencias y divergencias». En Teoría y Realidad Constitucional 32 (2013) pp. 139-158.

LUKES, S. «Cinco fábulas sobre los derechos humanos». En Shute, Stephen; y Hurley, Susan (eds); De los derechos humanos. Trotta, Madrid, 1998, pp. 29-46.

Matia Portilla, F. J. «De primacía, derechos y tribunales», en Gordillo PÉrez, Luis (coord.): Constitución española e integración europea. Treinta años de Derecho Constitucional de la integración. Valencia, Tirant lo Blanch, 2018.

— «Interpretación evolutiva de la constitución y legitimidad del matrimonio formado por personas del mismo sexo». En Teoría y Realidad Constitucional 31 (2013), pp. 541-554.

Monereo Atienza, C. Diversidad de género, minorías sexuales y teorías feministas. Dykinson, Madrid, 2015.

NowaK, M. «De la Comisión de Derechos Humanos al nuevo Consejo». En AlmQVIST, JeSsicA; y GómEZ IsA, FeliPe (coords.): El Consejo de Derechos Humanos. Oportunidades y Desafios, Universidad de Deusto, Bilbao, 2006, pp. 13-22.

OchOA RuIZ, N. Los mecanismos convencionales de protección de los derechos humanos en Naciones Unidas. Civitas, Madrid, 2004.

Ochoa Ruiz, N. y Salamanca Aguado, E. «El Consejo de Derechos Humanos de las Naciones Unidas. Un análisis preliminar». En Revista Electrónica de Estudios Internacionales 12 (2006), pp. 1-27.

Ovejero, F. La deriva reaccionaria de la izquierda. Página Indómita, Madrid, 2018.

Paletta, D. (coord.; y ed.); y Du Plessis, A. (dir.): Informe Anual, ILGA, 2017.

PAstor Ridruejo, J. A. «La globalización de los derechos humanos: El reto del siglo XXI». En Revista Europea de Derechos Fundamentales 2 (2003), pp. 19-34.

— «Prólogo». En Ochoa Ruiz, Natalia: Los mecanismos convencionales de protección de los derechos humanos en Naciones Unidas, Civitas, Madrid, 2004.

PeÑa DíAz, F. de A. La lucha que no cesa. Los derechos del colectivo LGTBI como derechos humanos. Tirant lo Blanch, Valencia, 2018.

PInKer, S. En defensa de la Ilustración. Paidós, Barcelona, 2018.

Piovesan, F.; y Kamimura, A. «Proteção internacional à diversidade sexual e combate à violência e discriminação baseadas a orientação sexual e identidade de gênero». Anuario de Derecho Público 1 (2017), pp. 173-190.

REID, G. «La homofobia como estrategia política». En Política Exterior 167 (2015), pp. 126-136.

—Lucha global por los derechos de las personas LGBT». En Política Exterior 157 (2014), pp. 1-8. 
RAwls, J. «Derecho de gentes». En Shute, Stephen; y Hurley, Susan (eds); De los derechos humanos. Trotta, Madrid, 1998, pp. 47-85.

Rodley, N. S.: «The role and impact of treaty bodies». En Shelton, David (ed.); The Oxford Handbook of International Human Rights Law. Oxford University Press, Oxford, 2013, pp. 621-648.

RORTY, R. «Derechos humanos: racionalidad y sentimentalidad». En Shute, Stephen; y Hurley, Susan (eds); De los derechos humanos. Trotta, Madrid, 1998, pp. 117-136.

SaIz Arnaiz, A. «Tribunal Constitucional y Tribunal Europeo de Derechos Humanos: las razones para el dialogo». En Asociación de Letrados DEL TRIBUnAL Constitucional: Tribunal Constitucional y diálogo entre tribunales. CEPC, Madrid, 2013, pp. 131-160.

Sperti, A. Constitutional Courts, Gay rights and sexual orientation equality. Hart Publishing, London, 2017.

Tirado Chase, A. «Human rights contestations: sexual orientation and gender identity». En The International Journal of Human Rights 20 (2016), pp. 703-723.

ViLlán Durán, C. «Luces y sombras del nuevo Consejo de Derechos Humanos», En Almqvist, Jessica; y Gómez Isa, Felipe (coords.): El Consejo de Derechos Humanos. Oportunidades y Desafios, Universidad de Deusto, Bilbao, 2006, pp. 23-36.

VILLAVERDE MENÉNDEZ, I. «El constitucionalismo líquido. La dogmática constitucional de los derechos fundamentales del siglo XXI tras 40 años de Constitución Española de 1978». En Punset Blanco, Ramón (coord.); Álvarez Álvarez, Leonardo (coord.); y Roca Martínez, José María (pr): Cuatro decadas de una Constitución normativa (1978-2018): Estudios sobre el desarrollo de la Constitución Española. Thomson Reuters-Civitas, Cizur Menor, 2018, pp. 31-51.

Voss, M. J. «Contesting Sexual Orientation and Gender Identity at the UN Human Rights Council». En Human Rights Review 19 (2018), pp. 1-22.

Xiol Ríos, J. A. «El diálogo entre Tribunales», en Asociación DE LETRADOS DEL Tribunal Constitucional: Tribunal Constitucional y diálogo entre tribunales. CEPC, Madrid, 2013, pp. 11-56.

ZIZEK, S. El coraje de la desesperanza. Crónicas del año en que actuamos peligrosamente. Anagrama, Barcelona, 2018. 


\title{
CAMINANTE, SE HACE CAMINO AL ANDAR. COMUNIDAD LGTBI, DERECHOS HUMANOS Y NACIONES UNIDAS
}

\author{
Walker, road is done when walking. \\ LGTBI Community, Human Rights and United Nations
}

\author{
Ignacio Álvarez Rodríguez \\ Profesor Ayudante Doctor de Derecho Constitucional \\ Universidad Complutense de Madrid \\ ialvarez1@ucm.es
}

http://dx.doi.org/10.18543/ed-67(1)-2019pp127-163

\section{Copyright}

Estudios de Deusto es una revista de acceso abierto, lo que significa que es de libre acceso en su in tegridad. Se permite su lectura, la búsqueda, descarga, distribución y reutilización legal en cualquier tipo de soporte sólo para fines no comerciales, sin la previa autorización del editor o el autor, siempre que la obra original sea debidamente citada y cualquier cambio en el original esté claramente indicado

Estudios de Deusto is an Open Access journal which means that it is free for full access, reading, search, download, distribution, and lawful reuse in any medium only for non-commercial purposes, without prior permission from the Publisher or the author; provided the original work is properly cited and any changes to the original are clearly indicated. 